This is the peer-reviewed version of the following article: Angew. Chem. Int. Ed., 2019, 58, 12761-12777, which has been published in final form at https://onlinelibrary.wiley.com/doi/full/10.1002/anie.201900932. This article may be used for non-commercial purposes in accordance with Wiley Terms and Conditions for Use of Self-Archived Versions.

\title{
IDPi Catalysis
}

\section{Lucas Schreyer, Roberta Properzi, and Benjamin List*}

Abstract: High acidity and structural confinement are the pivotal elements in asymmetric acid catalysis. The recently introduced imidodiphosphorimidate (IDPi) Brønsted acids have met with remarkable success in combining those features, acting as powerful Brønsted acid catalysts and "silylium" Lewis acid precatalysts in numerous thus far inaccessible transformations. Substrates as challenging to activate as simple olefins were readily transformed, ketones were employed as acceptors in aldolizations allowing sub-ppm level catalysis, whereas enolates of the smallest donor aldehyde, acetaldehyde, did not polymerize but selectively added a single time to a variety of acceptor aldehydes.

\section{IDPi in Organic Lewis Acid Catalysis}

For decades, the versatility and extraordinary potency of electron-deficient silanes as "silylium" Lewis acid catalysts has been exploited in $\mathrm{C}-\mathrm{C}$ and $\mathrm{C}$-heteroatom bond-forming reactions. Early examples comprise the $\mathrm{Me}_{3} \mathrm{SiOTf}_{-[}\left[{ }^{[1]}\right.$ and $\mathrm{Me}_{3} \mathrm{SiClO}_{4}{ }^{-[2]}$ catalyzed syntheses of nucleosides by Vorbrüggen and Krolikiewicz ${ }^{[3]}$ and the synthesis of homoallylic ethers from acetals and allyltrimethylsilane by the Noyori group. ${ }^{[4]}$ The groups of Ghosez ${ }^{[5]}$ and Mikami[6] independently identified the superior Lewis acidity and catalytic activity of silylated triflimide $\left(\mathrm{HNTf}_{2}\right), \mathrm{Me}_{3} \mathrm{SiNTf}_{2}$ (as compared to $\mathrm{Me}_{3} \mathrm{SiOTf}$ ), which was previously introduced by Foropoulos and DesMarteau, ${ }^{[7]}$ in several transformations including a Friedel-Crafts alkylation and a Diels-Alder reaction. It was later shown that silylated triflimide could be in situ generated from $\mathrm{HNTf}_{2}$ upon protodesilylation of a variety of nucleophilic silanes employed in addition reactions to carbonyl compounds. ${ }^{[8]}$ While the in situ generation of active "silylium" Lewis acid catalysts in this fashion represents a highly practical feature, their formation from weakly coordinating anions (" $X$ ") of chiral (e.g. transition metalbased) Lewis acids ("M") can be detrimental for enantioselective catalysis due to non-enantioselective "silylium" Lewis acid background catalysis (Figure 1a). Additionally, the Lewis basic chiral non-labile ligand(s) (" $L_{n}{ }^{*}$ ) can decrease the Lewis acidity of the metal center by $\sigma$ donation of electron density. For these reasons, "traditional"

[*] Dr. L. Schreyer, Dr. R. Properzi, Prof. Dr. B. List Max-Planck-Institut für Kohlenforschung Kaiser-Wilhelm-Platz 1, 45470 Mülheim an der Ruhr, Germany E-mail: list@mpi-muelheim.mpg.de a)

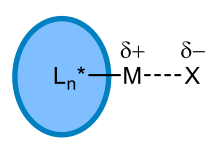

previous design of chiral Lewis acid catalysts

- ligand (= Lewis base) induces asymmetry but often decreases Lewis acidity

- potential "silylium" background catalysis

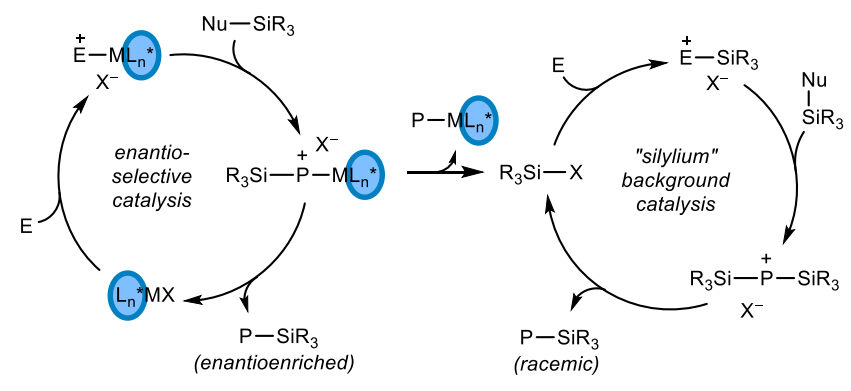

b)
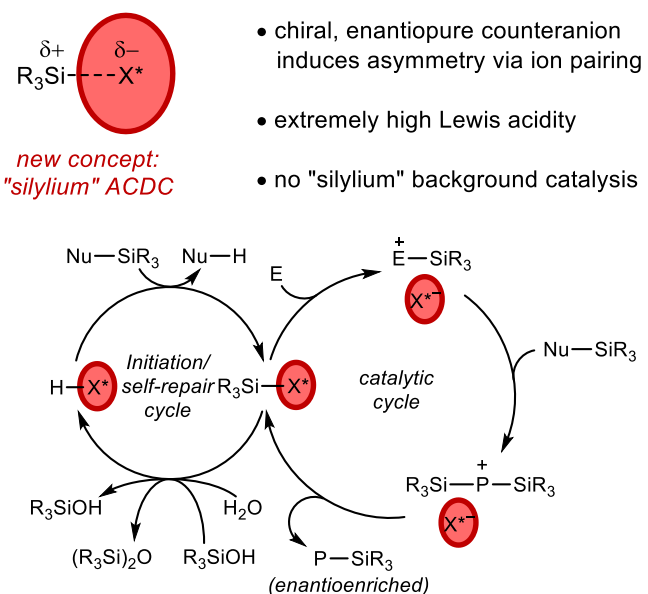

Figure 1. a) "Traditional" chiral Lewis acid catalyzed silyl-transfer reactions and "silylium" background catalysis. b) "Silylium" ACDC. $L_{n}{ }^{*}=$ chiral, enantiopure ligand(s), $M=$ metal(loid), $X=H$, alkyl or weakly coordinating anionic ligand, $R$ $=$ alkyl. $\mathrm{E}=$ electrophile, $\mathrm{Nu}=$ nucleophile, $\mathrm{P}-\mathrm{SiR}_{3}=($ silylated $)$ product, $\mathrm{X}^{*-}=$ chiral, enantiopure anion.

approaches to Lewis acid-catalyzed "silyl transfer" reactions (involving silane nucleophiles) often require high catalyst loadings of up to $20 \mathrm{~mol} \% .{ }^{\left[{ }^{[9]}\right.}$ An intriguing opportunity for the advancement rather than suppression of this type of catalysis arose when the concept of asymmetric counteranion-directed catalysis $(A C D C)^{[10]}$ was expanded to "silylium" Lewis acid organocatalysis (Figure 1b).

This advance became possible by the introduction of chiral disulfonimide (DSI) catalysts by the List group in 2009, which, unlike the previously reported BINOL-based phosphoric acids, ${ }^{[11,12]}$ proved sufficiently acidic to afford catalytically active "silylium" Lewis acids upon in situ silylation. ${ }^{[13,14]}$ 
While addition reactions of various nucleophilic silanes to aldehydes, including silyl ketene acetals, allylsilanes and dialkyl silyl phosphites, ${ }^{[15]}$ were achieved with excellent enantioselectivities, a general limitation has remained unaddressed with DSI catalysis. Specifically, the transformation of small, unbiased aliphatic aldehydes proceeded with significantly diminished efficiency and enantioselectivity compared to that of aromatic aldehydes due to their lower reactivity and the more challenging enantiofacial discrimination. ${ }^{[15]}$ A breakthrough in this regard, which was also limiting the applicability of BINOL-derived phosphoric acids in Brønsted acid catalysis, was subsequently achieved by Čorić and List by the development of imidodiphosphate (IDP) Brønsted acids. ${ }^{[16]}$ In contrast to the open active site displayed by both BINOL-based phosphoric acids and DSIs, IDPs are sterically highly confined acids, the core of which is buried inside two 3,3'-disubstituted BINOL units, allowing for exceptionally high levels of stereoinduction even with unfunctionalized, aliphatic substrates. ${ }^{[17]}$ Yet, the reduced acidity of IDPs ( $\mathrm{p} K_{\mathrm{a}}=11.5$ in $\mathrm{MeCN}$ ) as compared to DSIs $\left(\mathrm{p} K_{\mathrm{a}}=8.4\right.$ in MeCN) limited their applicability in Brønsted acid catalysis and made them incompatible with "silylium" Lewis acid catalysis. ${ }^{[14,18]}$ The quest to overcome the existing barriers regarding reactivity and selectivity has become a quest for the combination of the high catalytic activity of DSIs and the steric confinement of IDPs. Ultimately, this goal was realized upon application of a concept developed earlier by the Yagupolskii group, consisting of the tremendous acidifying effect upon the replacement of $\mathrm{O}$ atoms by NTf groups in benzoic acid, to the IDP motif (Figure 2). ${ }^{[19]}$

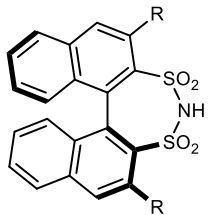

Disulfonimides (DSI)

+ highly active Brønsted acids $\mathrm{pK} \mathrm{K}_{\mathrm{a}}(\mathrm{MeCN})=8.4$

+ active in Lewis acid catalysis

$\sim$ moderately stereoselective

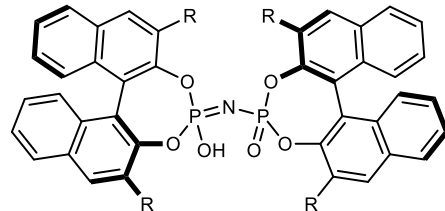

$$
\text { Imidodiphosphates (IDP) }
$$

$\sim$ moderately active Brønsted acids $\mathrm{pK} \mathrm{K}_{\mathrm{a}}(\mathrm{MeCN})=11.5$

- inactive in Lewis acid catalysis

+ highly stereoselective

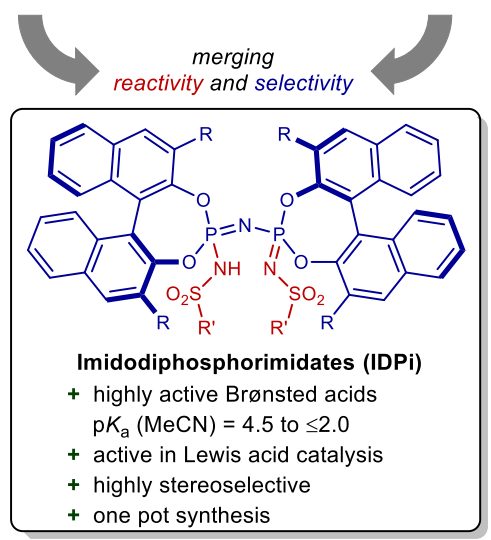

Figure 2. Imidodiphosphorimidate (IDPi) catalysts: merging reactivity and selectivity.

The profoundly enhanced acidity $\left[\mathrm{p} K_{\mathrm{a}}=4.5\right.$ to $\leq 2.0$ in $\mathrm{MeCN}$ (depending on substituents $\left.\left.R \quad \& \quad R^{\prime}\right)\right]^{[14]}$ of the imidodiphosphorimidates (IDPi) created in this approach made them promising candidates for the exploration of new reactivities in asymmetric organic Lewis acid catalysis.

\subsection{The Hosomi-Sakurai Allylation of Aldehydes}

The allylation of aldehydes to produce secondary homoallylic alcohols is amongst the most frequently employed $\mathrm{C}-\mathrm{C}$ bond-forming reactions in chemical synthesis. ${ }^{[20]}$ Since the first report of an enantioselective variant of this transformation by Herold and Hoffmann in 1978, ${ }^{[21]}$ employing a camphorderived chiral allylboronate reagent, a true myriad of enantioselective allylation methods on the basis of chiral auxiliaries $^{[22]}$ and catalysts ${ }^{[20]}$ has been reported. Enantioselective allylations with the inexpensive, non-toxic, air- and moisture-stable allyltrimethylsilane, however, have remained challenging. This reagent, which was first used in Lewis acid-mediated allylations of aldehydes and ketones by Hosomi and Sakurai in $1976,{ }^{[23]}$ is a very poor nucleophile, ${ }^{[24]}$ thus requiring strong Lewis acids for a sufficient activation of the carbonyl electrophiles. In turn, such catalysts can initiate competing non-enantioselective "silylium" Lewis acid background catalysis, owed to the formation of catalytically highly active, electron-deficient silanes with the weakly coordinating anions of the Lewis acid. ${ }^{[9]}$
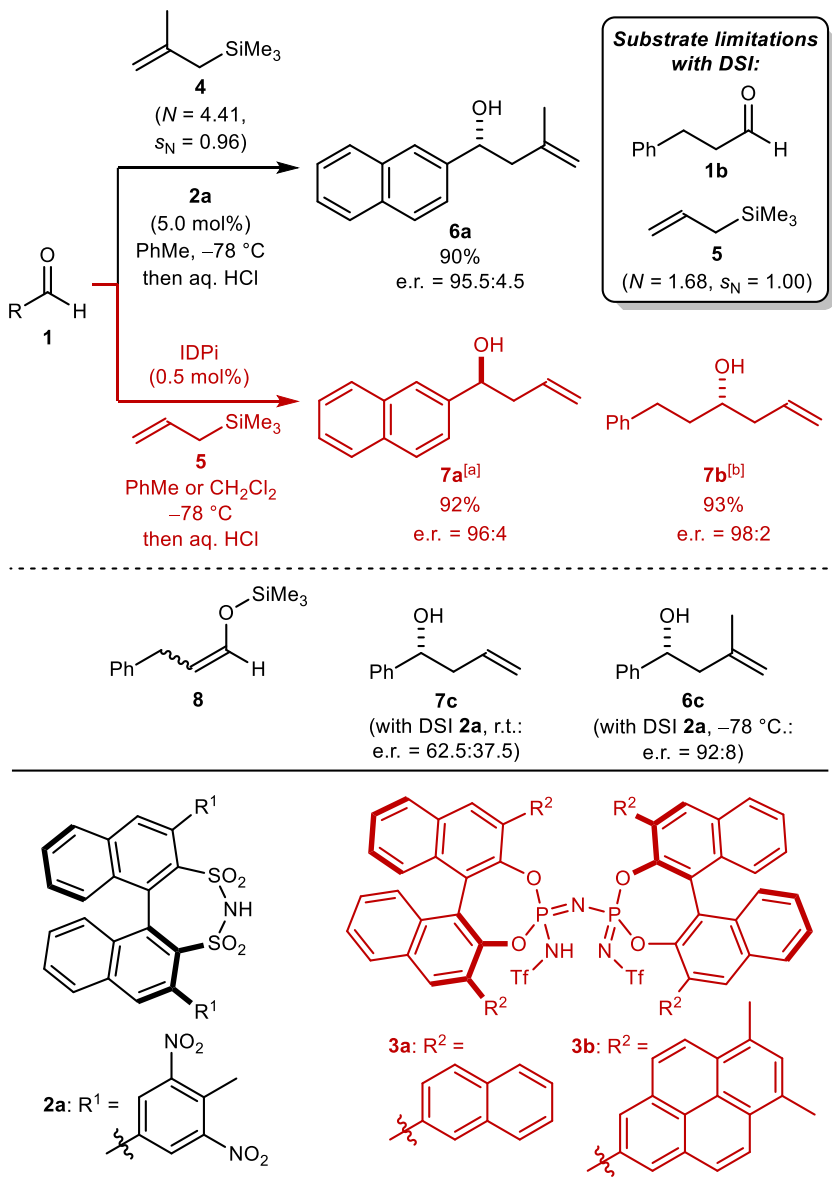

Scheme 1. Comparison of the catalytic performances of DSI and IDPi catalysts in the Hosomi-Sakurai allylation. [a] Using IDPi ent-3a. [b] Using IDPi 3b. 
Lucas Schreyer studied chemistry at the University of Vienna, from which he received his MSc degree in 2014 after a research stay in the group of Prof. Dr. Dirk Trauner at the Ludwig-Maximilians-Universität München, working on the total syntheses of caribenols $A$ and $B$. He subsequently commenced his doctoral studies in the group of Prof. Dr. Benjamin List at the MaxPlanck-Institut für Kohlenforschung, working on the development and application of new chiral Brønsted acids as precatalysts in asymmetric "silylium" Lewis acid catalysis, for which he was awarded a Ph.D. in 2018 from the University of Cologne.

Roberta Properzi studied chemistry at the University of Camerino, from which she received her Ph.D. degree in 2014 under the guidance of Prof. Enrico Marcantoni, with a Ph.D. fellowship awarded by Pfizer Italia. She conducted research on the synthesis of medicinally relevant heterocycles, promoted by Lewis acids or via sequential one-pot oxidation-rearrangement of propargylamines. The latter studies were carried out at Pfizer Worldwide R\&D in

Groton (CT, USA), under the supervision of

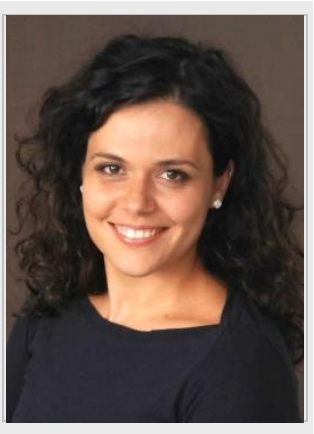

Dr. Jeremy T. Starr. Subsequently, she joined Prof. Benjamin List's group at the Max-Planck-Institut für Kohlenforschung as postdoctoral fellow, working on asymmetric Brønsted and Lewis acid catalyzed transformations.

Benjamin List was born in 1968 in Frankfurt, Germany. He graduated from Freie University Berlin (1993) and received his Ph.D. (1997) from the University of Frankfurt. After postdoctoral studies (19971998) as a Feodor Lynen Fellow of the Alexander von Humboldt foundation at The Scripps Research Institute, he became a Tenure Track Assistant Professor there in January 1999. Subsequently, he developed the first proline-catalyzed asymmetric intermolecular aldol-, Mannich-, Michael-,

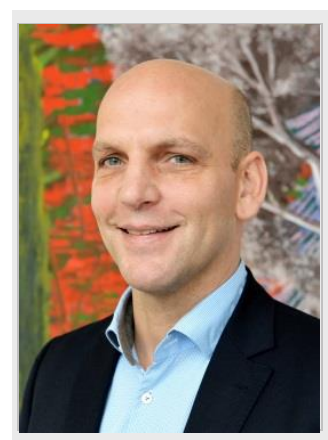
and $\alpha$-Amination reactions. In 2003 he moved to the Max-Planck-Institut für Kohlenforschung, where he has been a director since 2005. From 2012 until 2014 he has been the managing director of the institute. Since 2004 he also serves as an honorary professor at the University of Cologne. His research interests are new catalysis concepts and chemical synthesis in general. He has pioneered several concepts including aminocatalysis, enamine catalysis, and asymmetric counteranion-directed catalysis (ACDC). His accomplishments have been recognized with the Otto Bayer Prize (2012), the Mukaiyama Award (2013), the Cope-Scholar Award (2014), the Gottfried Wilhelm Leibniz Prize (2016), and a recent election to the German National Academy of Sciences Leopoldina (2018).
Previous reports on enantioselective variants such as Yamamoto's chiral acyloxyborane Lewis acids, ${ }^{[25]}$ as well as Carreira's TiF $4 /$ BINOL system, ${ }^{[26]}$ successfully suppressed this type of background catalysis, however each of these methods only performed well with the significantly more nucleophilic 2-alkylated allyltrimethylsilanes, ${ }^{[27]}$ or with only a specific class of substrates. In 2012, the List group tackled this problem for the first time through employment rather than suppression of "silylium" Lewis acid catalysis within the concept of asymmetric counteranion-directed catalysis (ACDC), ${ }^{[28]}$ introduced earlier by Mayer and List. ${ }^{[10]}$ While in situ silylated DSI 2 a enabled highly enantioselective additions of methallyltrimethylsilane (and other 2-substituted allyltrimethylsilanes) to a broad range of (hetero)aromatic and vinylogous aromatic aldehydes, its acidity/catalytic activity proved insufficient for the transformation of aliphatic aldehydes such as 3-phenylpropanal (1) b), affording the desired homoallylic alcohol in low yields due to side-reactions (formation of enolsilane $\mathbf{8}$ upon deprotonation) and in almost racemic form (Scheme 1). Moreover, the parent allyltrimethylsilane (5) was unreactive under the cryogenic conditions required for high levels of stereoinduction as in the case with methallyltrimethylsilane (4), thus furnishing alcohol 7c at r.t. in high yield but a poor enantiomeric ratio (e.r.) of 62.5:37.5 (cf:: methallylation of benzaldehyde (1c) at $-78^{\circ} \mathrm{C}$ afforded alcohol $6 \mathrm{c}$ in $82 \%$ yield and an e.r. of $92: 8) .{ }^{[28]}$

Table 1. Selected substrates for the IDPi-catalyzed Hosomi-Sakurai allylation of aldehydes.

(1.5 equiv)


In contrast, IDPi ent-3a and $\mathbf{3 b}$ exhibited remarkable catalytic activities in the allylation of 2-naphthaldehyde (1a) and 3-phenylpropanal (1) ), allowing for efficient transformations of both substrates under cryogenic conditions at catalyst loadings as low as $0.5 \mathrm{~mol} \% .^{[29]}$ Intriguingly, pure $n$-alkyl aliphatic aldehydes such as decanal (1d) and pentanal (1e), which are typically among the most challenging substrates regarding enantiofacial differentiation, as well as the $\beta$ branched isovaleraldehyde (1f) provided the corresponding homoallylic alcohols $\mathbf{7 d - f}$ in high yields and excellent e.r. (Table 1, Entries 1-3). $p$ - and $m$-Methylbenzaldehyde (1 $\mathbf{g}$ and $\mathbf{1 h}$, respectively) as well as cinnamaldehyde (1i) were transformed with similarly high efficiency, using IDPi ent-3a (Entries 4-6). In the case of (S)-2-phenylpropanal [(S)-1j], a "matched/mismatched" situation depending on catalyst and substrate configuration was observed. While $(R)$-BINOLderived IDPi ent-3b afforded alcohol syn-7j with only poor diastereoselectivity (d.r. $=65: 35$ ), the corresponding $(S)$ BINOL derived IDPi $\mathbf{3 b}$ gave rise to the anti diastereomer in an excellent d.r. of 98.5:1.5.

Impressive solutions were offered for some particularly challenging substrates in this transformation. Yet, an expansion of the substrate scope to $\alpha$-branched aldehydes including strictly catalyst-controlled diastereoselective allylations of chiral substrates have remained elusive and highly attractive targets, which in light of the ever increasing diversity of IDPi catalysts can be expected to be solved in the future.

\subsection{Asymmetric Catalysis via Cyclic, Aliphatic Oxocarbenium lons}

Substituted oxacycles constitute carbohydrates and occur in numerous other classes of drugs and natural products. This motif is frequently accessed through $\mathrm{S}_{N} 1$-type substitution reactions involving cyclic oxocarbenium ${ }^{*}$ ions. ${ }^{[30]}$ While numerous methods for stereoselective intermolecular substitution reactions of this type have been developed in recent years, they so far have involved further stabilizing functionalities which additionally facilitate enantiofacial differentiation, such as annulated aromatic ring systems, ${ }^{[31]}$ or Lewis basic sites that engage in neighboring group effects, as is typically applied in glycosylation reactions. ${ }^{[30 a]}$ In contrast, enantioselective nucleophilic addition reactions to simple aliphatic, cyclic oxocarbenium ions affording substituted tetrahydrofurans and -pyrans have remained an unsolved challenge (Figure 3). This challenge was taken up by the List group, who examined several previously developed chiral Brønsted acids ${ }^{[13,16]}$ for the substitution reaction of lactol acetate 9 with silyl ketene acetal 10 via postulated ion pair intermediate 11 (Table 2). ${ }^{18]}$

On the one hand, DSI $\mathbf{2 b}$ proved catalytically highly active in this transformation, however its open active site did not allow for any measurable level of stereoinduction.

On the other hand, IDP 13a, a highly potent catalyst in spiroacetalizations proceeding through 2-alkylated cyclic

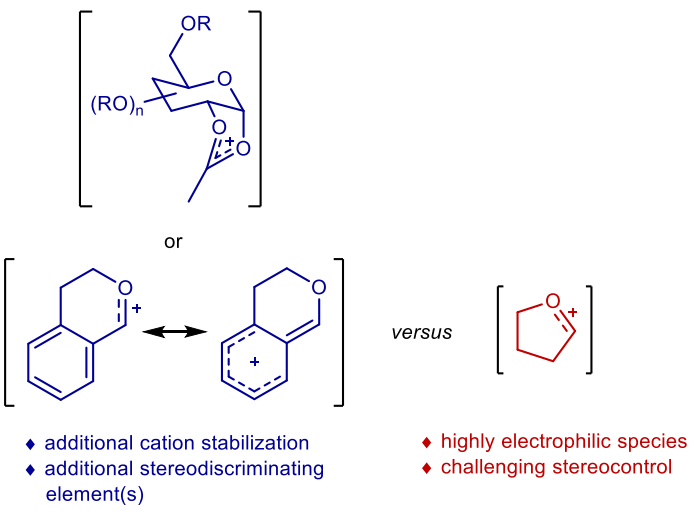

Figure 3. Different types of cyclic oxocarbenium ions: neighboring group effect and resonance stabilization (blue), no additional stabilization (red).

Table 2. Examination of different chiral Brønsted acids developed by the List group for the synthesis of tetrahydrofuran $\mathbf{1 2}$ from lactol acetate $\mathbf{9}$ and silyl ketene acetal $\mathbf{1 0 .}$

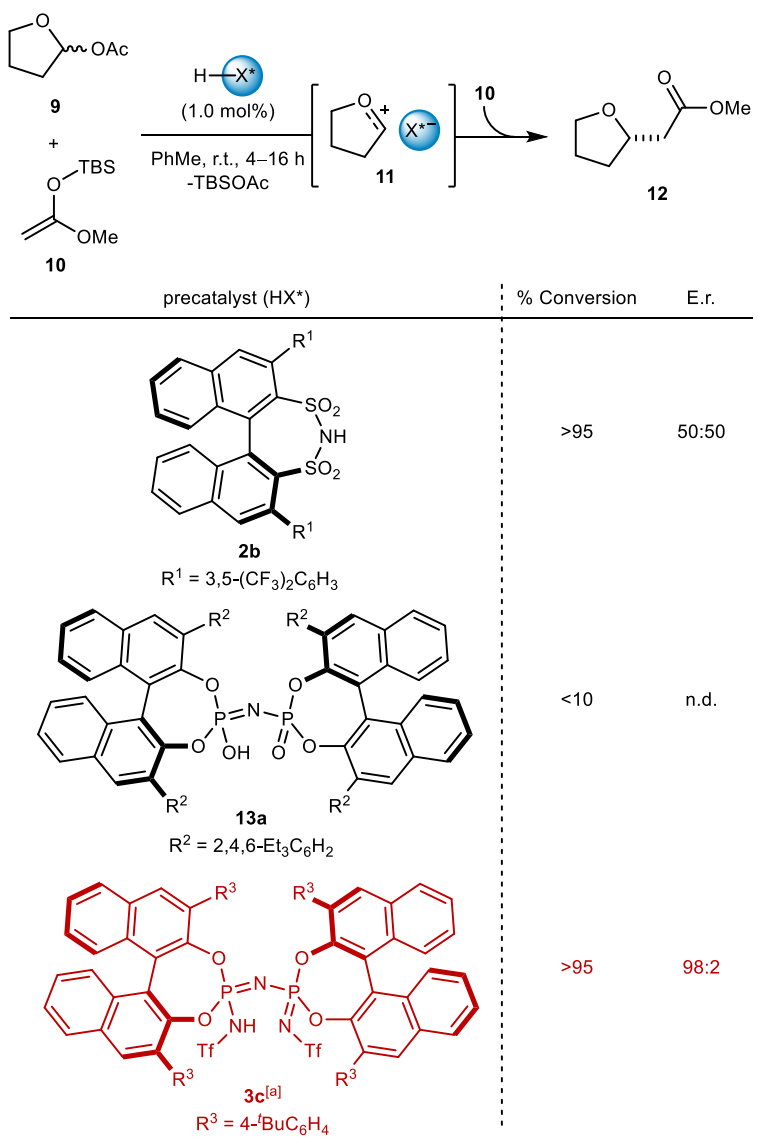

[a] Reaction conducted at $-78^{\circ} \mathrm{C}$.

oxocarbenium ion intermediates, ${ }^{[16]}$ was insufficiently active for the abstraction of the acetate anion from the substrate. In contrast, IDPi 3c not only exhibited exceptionally high catalytic activity even under cryogenic conditions, but further provided tetrahydrofuran 12 in an outstanding e.r. of 98:2. [18]

\footnotetext{
"In this work, the term "oxocarbenium ion" is used as synonym for the more accurate, yet scarcely applied term "carbonylonium ion" (cf. Beilstein J. Org. Chem. 2018, 14, 2568-2571).
} 
Aside from differently substituted THFs (Table 3, Entries 1-3), also a substituted tetrahydropyran (THP), oxepane and chromane could be accessed in high yields and excellent enantioselectivities (Entries 4-6). Under the same reaction conditions, using 2.4 equivalents of silyl ketene acetal, a mixture of all stereoisomers of diacetate $\mathbf{2 2}$ was stereoconvergently transformed into tetrahydrofuran 20 in high yield, diastereo- and enantioselectivity (Entry 7). ${ }^{[18]}$

Table 3. Selected examples of the substrate scope of the synthesis of substituted oxacycles.

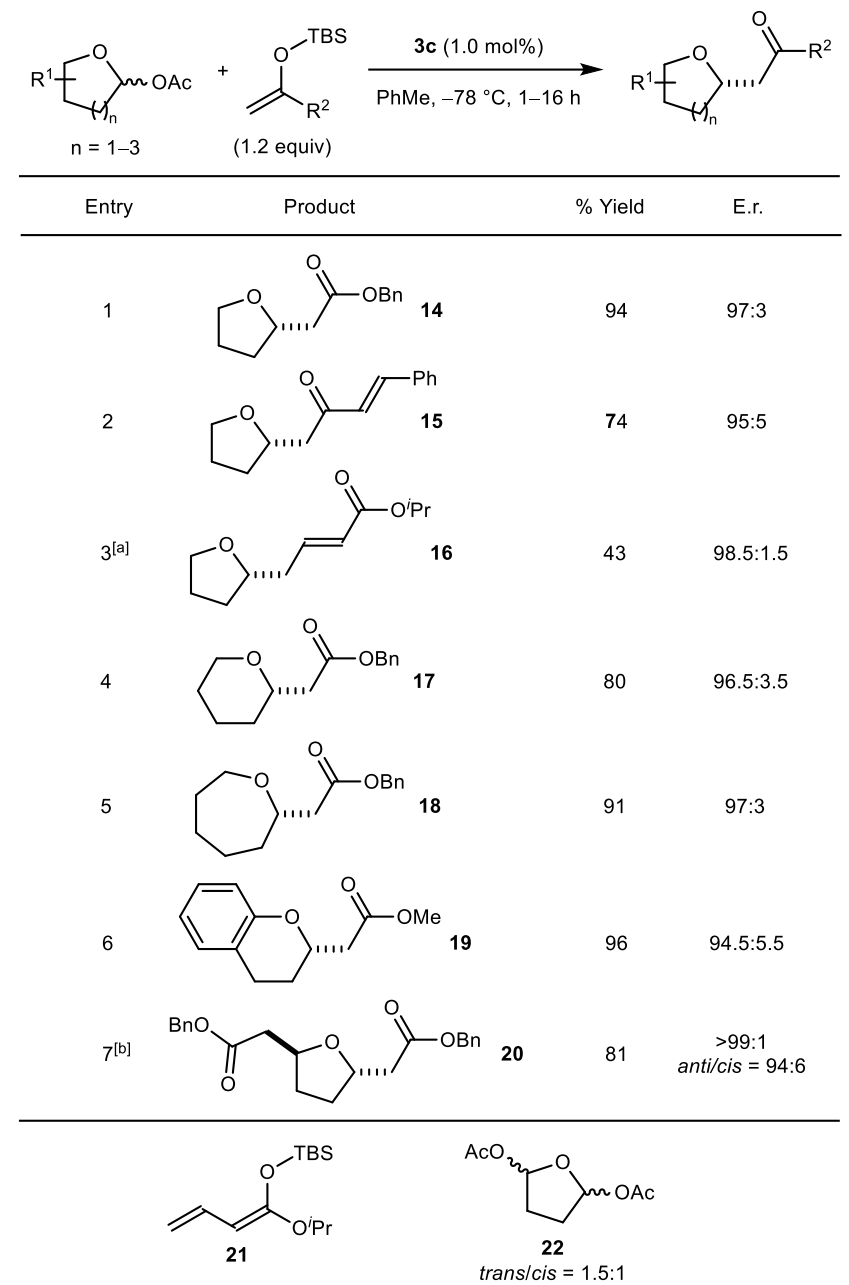

[a] Using silyl ketene acetal 21. [b] Starting from diacetate 22 (mixture of all stereoisomers).

In a more recent report, the List group has expanded enantioselective addition reactions to cyclic oxocarbenium ions to the synthesis of difficult to access 2,2-disubstituted and higher decorated THFs and THPs, starting from 1,4- and 1,5-ketoaldehydes or diketones (Table 4). This approach utilizes a chemoselective Lewis acid-catalyzed cyclization of the dicarbonyl substrate, favoring the intramolecular addition of the ketone to the aldehyde, and allows for the employment of silanes as well as several carbon nucleophiles for highly diastereo- and enantioselective syntheses of the targeted compounds. ${ }^{[32]}$
Table 4. Selected examples for the synthesis of 2,2-di- and higher substituted THFs from 1,4-dicarbonyls.
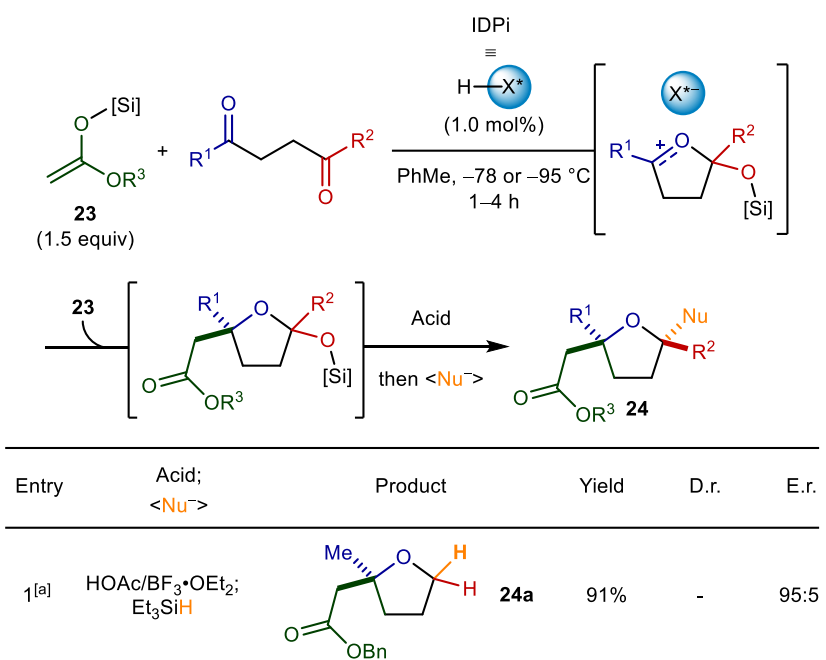

$2^{[a]}$

$4_{4}^{[\mathrm{b}]} \mathrm{SiMe}_{3}{ }_{\mathrm{OMe}}^{\mathrm{Me}_{3} \mathrm{SiOH} / \mathrm{BF}_{3} \cdot \mathrm{OEt}_{2} ;}$ $5^{[\mathrm{b}]} \underset{\mathrm{Me}_{3} \mathrm{Al}}{\mathrm{Me}_{3} \mathrm{SiOH} / \mathrm{BF}_{3} \cdot \mathrm{OEt}_{2} ;}$

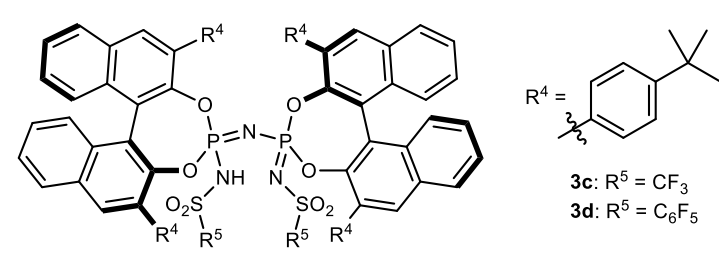

[a] Using IDPi 3d. [b] Using IDPi ent-3c.

\subsection{A Mukaiyama-Michael Reaction of Silyl Ketene Acetals and $\alpha, \beta$-Unsaturated Methyl Esters}

While the addition of silyl ketene acetals to cyclic, aliphatic oxocarbenium ions was primarily challenged by their difficult enantiofacial discriminations (cf. Chapter 1.2), $\alpha, \beta$ unsaturated esters as electrophiles in enantioselective Mukaiyama-Michael reactions additionally suffer from an inherently low electrophilicity, as recently reported by the Mayr group (Figure 4). ${ }^{[33]}$ As a consequence, asymmetric Michael reactions have thus far been largely limited to enals and enones as electrophiles. ${ }^{[34]}$ 


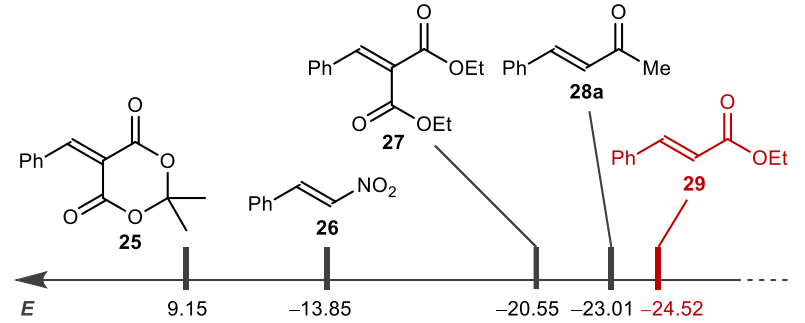

Figure 4. Electrophilicity parameters $(E)$ of different Michael acceptors.

In contrast, examples with $\alpha, \beta$-unsaturated esters have remained rare, ${ }^{[35]}$ and more commonly the critical ester moiety has been replaced by more electrophilic analogues, such as $\mathrm{N}$-acyl oxazolidinones, $\mathrm{N}$-acyl imides, $\mathrm{N}$-acyl imidazolides, $\alpha$ ketophosphonates and other activated species, thereby significantly diminishing the step- and atom economy. ${ }^{[36]} \alpha, \beta$ Unsaturated esters have recently been successfully employed as substrates in enantioselective, organic Lewis acidcatalyzed Diels-Alder reactions with cyclopentadiene, using an in situ silylated binaphthyl-allyl-tetrasulfone (BALT) 33 catalyst. ${ }^{[37]}$

Table 5. Assessment of different chiral Brønsted acids for the Mukaiyama-Michael addition of silyl ketene acetal $\mathbf{3 0}$ to methyl cinnamate (31a)
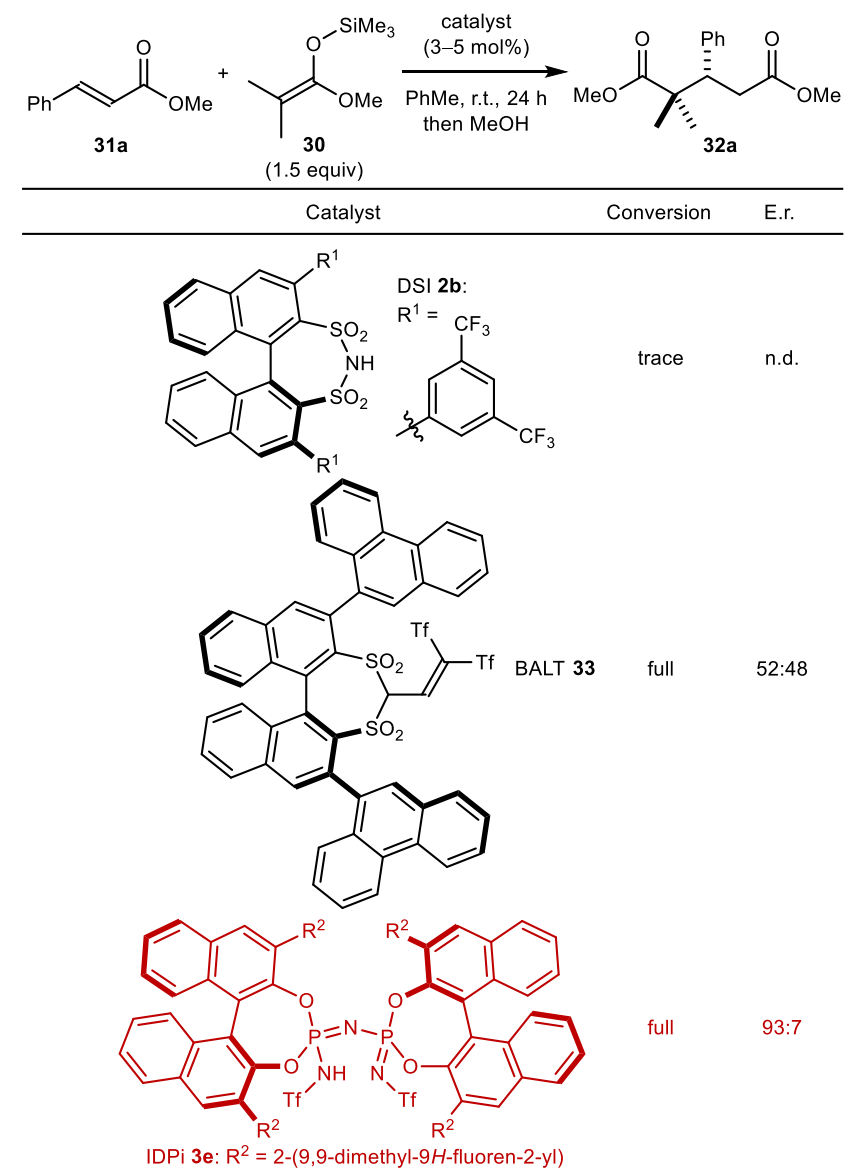

In contrast to DSI $\mathbf{2 b}$, BALT $\mathbf{3 3}$ provided sufficient catalytic activity to allow the addition of silyl ketene acetal $\mathbf{3 0}$ to methyl cinnamate (31a), however with almost no enantioselectivity (Table 5). Intriguingly, IDPi $3 e$ not only proved equally active in the targeted transformation, but afforded diester 32a in a high e.r. of 93:7. ${ }^{[38]}$ Upon changing the solvent to cyclohexane and lowering the reaction temperature to $0^{\circ} \mathrm{C}$, diester $32 \mathrm{a}$ was obtained in $97 \%$ yield and an even elevated e.r. of $97: 3$, using as little as $1.0 \mathrm{~mol} \%$ of IDPi $3 e$ (Table 6, Entry 1). Other cinnamate derivatives, as well as $\beta$-alkyl substituted acrylate 31d were well tolerated substrates and furnished the desired products in high yields and enantioselectivities (Entries 2-4). In the case of 2-monosubstituted silyl ketene acetal 34, the configuration of the nucleophile strongly affected the d.r. of the product. While silane $(E)-34$ afforded diester syn-32e in high yield, diastereo- (d.r. $=92.5: 7.5)$ and enantioselectivity (e.r. $=99: 1$ ), silane $(Z)-34$ resulted in the preferred formation of the anti-diastereomer of the product (anti-32e), albeit with a diminished d.r. of $61.5: 38.5$ (Entries 5-6). ${ }^{[38]}$

Table 6. Selected examples of the substrate scope of the IDPi-catalyzed Mukaiyama-Michael addition to methyl esters $\mathbf{3 1}$.

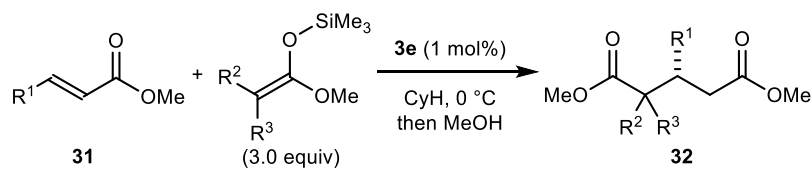

\begin{tabular}{llclll}
\hline Entry & Product 32 & $\begin{array}{c}\text { Silyl ketene } \\
\text { acetal }\end{array}$ & $\mathrm{t}$ & $\%$ Yield & E.r. \\
\hline
\end{tabular}

1 MeO<smiles>COC(=O)C(C)(C)[C@H](CCC(C)=O)c1ccccc1C</smiles><smiles>CCCCCCC[C@H](CC(=O)OC)C(C)(C)C(C)(C)C</smiles>

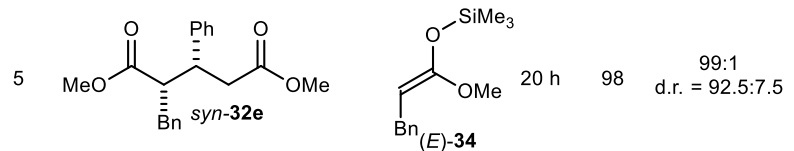<smiles>COC(=O)CC(C(Br)C(=O)OC)[C@H](Br)c1ccccc1</smiles> 


\subsection{A Mukaiyama Aldol Addition of Silyl Ketene Acetals to Ketones: Approaching sub-ppm-level Asymmetric Organocatalysis}

Few reactions have caught as much attention by organic chemists as the aldol reaction, judged by the myriad of auxiliary- and catalyst-based stereoselective methods developed in the past decades. ${ }^{[39]}$ Despite all continuous advances in this field, ketone acceptors have remained a challenging class of substrates in catalytic enantioselective variants of this transformation. Due to the reduced steric dissimilarity of the carbonyl-bound substituents in ketones as compared to aldehydes, enantiofacial differentiations are typically significantly more difficult to accomplish. Yet more fundamental obstacles consist of the lower reactivity of ketones as electrophiles (as compared to aldehydes) due to both steric and electronic reasons, as well as the fact that aldolizations with pre-formed (e.g. ester) enolates are typically thermodynamically disfavored. ${ }^{[40]}$ This thermodynamic preference of the retro-aldol reaction is effectively inverted by employment of the corresponding ester-derived silyl ketene acetals, and the groups of Denmark, and later those of Kanai and Shibasaki have succeeded in developing enantioselective Lewis base-catalyzed additions of a trichlorosilyl ketene acetal, ${ }^{[41]}$ and $\mathrm{Cu}(\mathrm{I})$-catalyzed additions of a trimethylsilyl ketene acetal to ketones, respectively. ${ }^{[42]}$ Drawbacks of both methods, however, aside from limitations regarding specific substrates, include either the necessity for high catalyst loading $(10 \mathrm{~mol} \%),{ }^{[41]}$ or a rather complex reaction setup. ${ }^{[42]}$ While the DSI-catalyzed addition of silyl ketene acetals to aldehydes proved possible with catalyst loadings as low as $0.01 \mathrm{~mol} \%$ (100 ppm), ${ }^{[13]}$ ketone 28b exclusively afforded enolsilane 35 upon $\alpha$-deprotonation of the activated electrophile (Scheme 2).

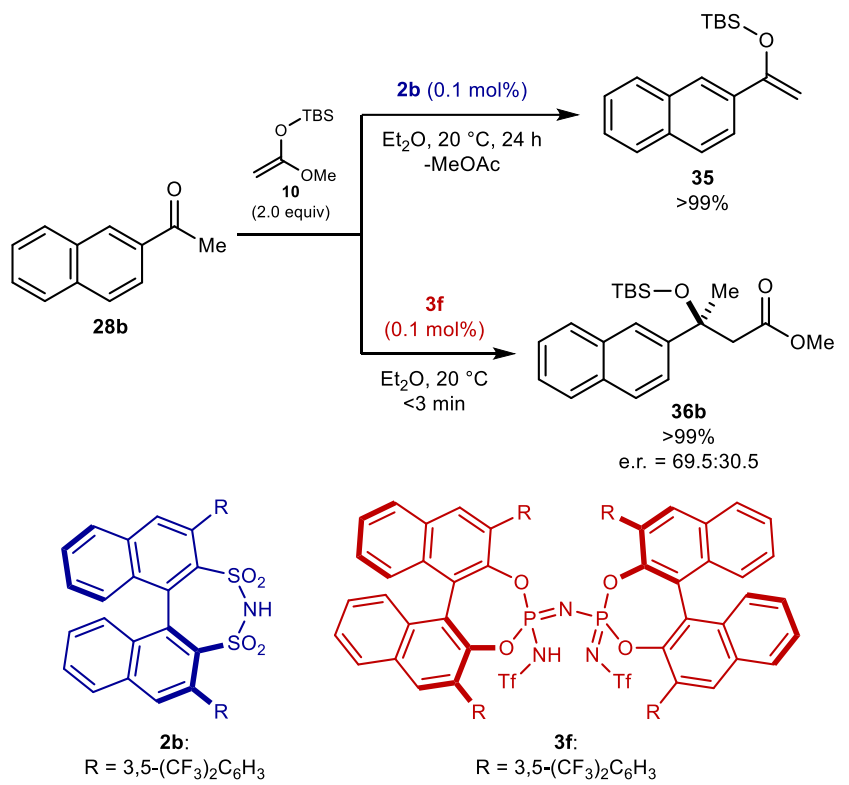

Scheme 2. Orthogonal chemoselectivities with DSI and IDPi in the targeted Mukaiyama aldol reaction with ketone electrophiles: deprotonation (DSI 2b) versus addition (IDPi $\mathbf{3 f}$ ).

In contrast, the List group showed that the significantly less Brønsted basic IDPi $\mathbf{3 f}$ successfully overcame this limitation in chemoselectivity and cleanly afforded aldol $\mathbf{3 6}$ b in almost quantitative yield and with promising enantioselectivity. ${ }^{[43]}$ The replacement of the trifluoromethyl groups in the 3,5-positions of phenyl substituent "R" of IDPi $3 f$ by $n$-alkyl groups (3g: $n$-propyl, $\mathbf{3 h}$ : $n$-hexyl) effected a profound increase in enantioselectivity. With IDPi $\mathbf{3 h}$ $(0.05 \mathrm{~mol} \%=500 \mathrm{ppm})$, the model reaction (cf. Scheme 2) afforded aldol $\mathbf{3 6 b}$ in $99 \%$ yield and an excellent e.r. of 97:3.

Table 7. Selected examples of the scope of ketones of the Mukaiyama aldo reaction with silyl ketene acetal 10 .

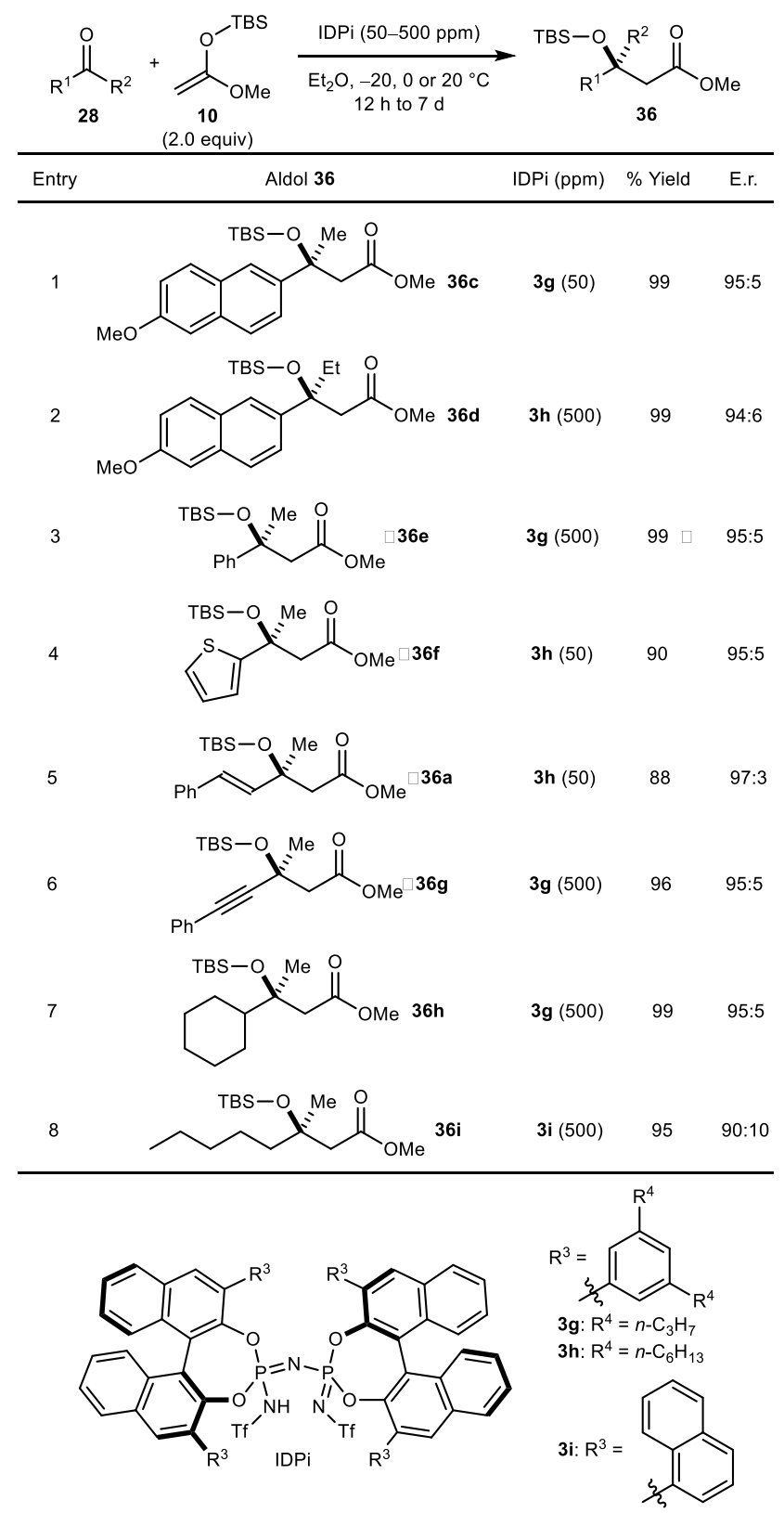

A range of aryl alkyl ketones, dialkyl ketones and enones were shown to perform very well with IDPis $\mathbf{3 g}$ and $\mathbf{3 h}$ (and in the case of 2-heptanone: with 1-naphthyl-substituted IDPi 3i), with catalyst loadings as low as $50-500$ ppm (Table 7, Entries 1-8). [4] $^{\text {[3] }}$

To explore the limits of the catalytic activity, the reaction furnishing aldol 36a was performed on a multi-decagram scale (Table 8). As little as $0.37 \mathrm{mg}\left(1.9 \cdot 10^{-4} \mathrm{mmol}, 2.8 \mathrm{ppm}\right)$ of IDPi 3h fully converted ketone 28a (each $10.0 \mathrm{~g}, 68.4 \mathrm{mmol}$ ) and silyl ketene acetal 10 (14.2 g, 75.2 mmol, 1.1 equiv) in a small 
amount of $\mathrm{Et}_{2} \mathrm{O}(8.55 \mathrm{~mL})$. After removal of the volatiles, two further batches, each of the same amounts of both substrates in $\mathrm{Et}_{2} \mathrm{O}$, were consecutively added to the crude mixture, ultimately reaching $95 \%$ conversion of all subjected ketone $28 \mathbf{a}$ and allowing for the isolation of aldol 36 a in $82 \%$ yield and an e.r. of $95: 5$, corresponding to an outstanding total turnover number (TON) of $9.11 \cdot 10^{5} .{ }^{[43]}$

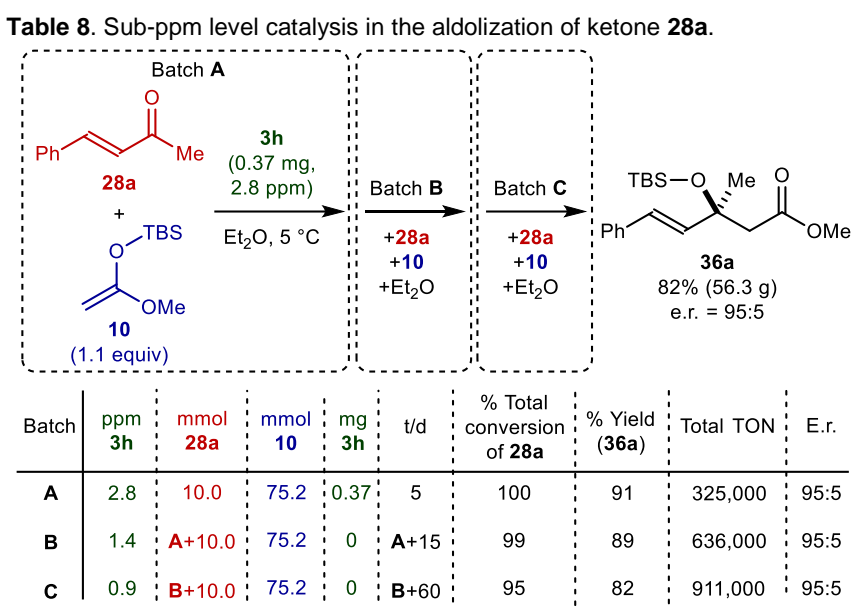

\subsection{Asymmetric Single Aldolizations of Acetaldehyde Enolsilanes}

While ketones represent a particularly challenging class of acceptors in enantioselective aldolizations (cf. Chapter 1.4 of this review), the most challenging donors are undoubtedly those that produce another reactive acceptor unit in the course of the reaction, i.e. aldehydes. ${ }^{[4]}$ The consequential problems include the proneness of such processes to yield oligomers and additional critical features such as the limited stability of those aldol products. For a long time they have been circumvented by the stepwise asymmetric construction of $\beta$-oxyaldehydes via less reactive synthons, i.e. homoallylic alcohols $^{[45]}$ and $\beta$-hydroxyesters/-thioesters. ${ }^{[46]}$ Only more recently, chemists have taken on the prestigious challenge of enantioselective single aldolizations between aldehydes, which were previously only possible with enzymes. ${ }^{[47]}$ After Denmark's first report in 2001, comprising Lewis basecatalyzed indirect aldol reactions with aldehyde-derived trichlorosilyl enolates, ${ }^{[48]}$ various Lewis base-catalyzed direct cross-aldol reactions followed.[49] The employment of the smallest donor aldehyde, acetaldehyde, however has remained problematic. The few reports therewith face severe limitations in acceptors to non-enolizable, typically electronpoor aldehydes, and moreover produce unstable aldol products, requiring in situ derivatizations of the valuable aldehyde moiety. ${ }^{[50]}$ In contrast, $\beta$-silyloxy aldehydes, the products of the Mukaiyama aldol reaction with aldehyde-derived enolsilanes, are significantly more stable and can even be isolated by conventional purification methods. While powerful Lewis acid catalysts such as silylated triflimide readily promote this transformation, it does not differentiate between substrate and product aldehydes and causes oligomerization with common, simple silyl groups such as triethylsilyl (TES). ${ }^{[51]}$ In 2006, Boxer and Yamamoto successfully addressed this limitation by employment of the exceptionally bulky tris(trimethylsilyl)silyl group, allowing for highly selective single and - depending on the stoichiometry - double aldolizations of aromatic and aliphatic acceptor aldehydes (Table 9). ${ }^{[52]}$

Table 9. Mukaiyama aldol reaction with enolsilanes of acetaldehyde: Reagent control, non-enantioselective (red); catalyst control, enantioselective (blue).

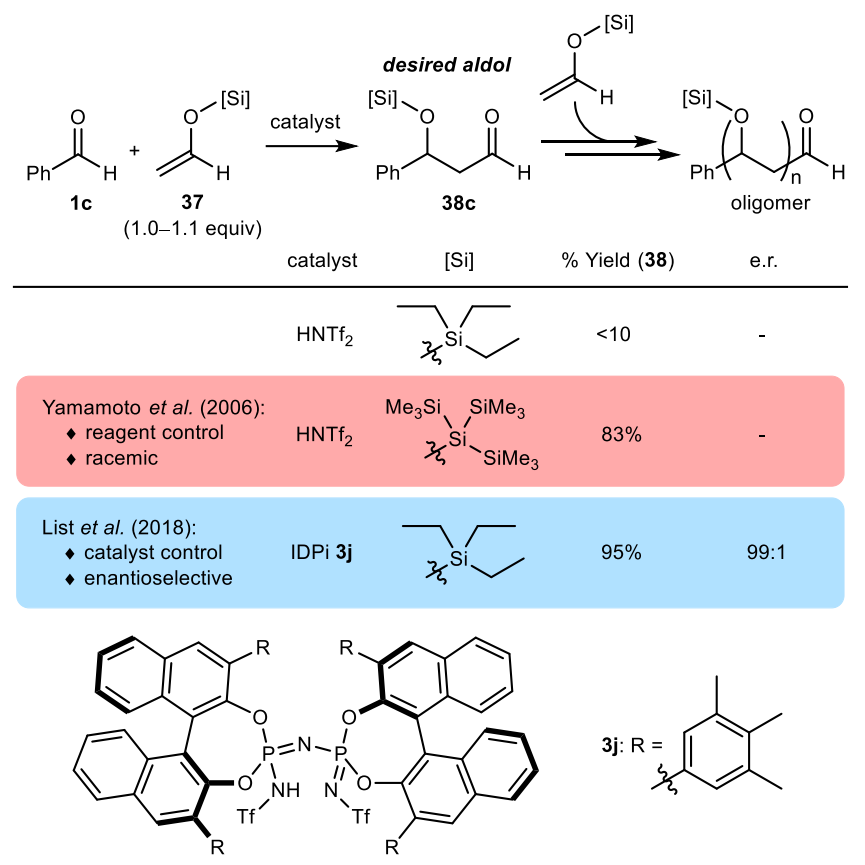

An enantioselective variant of this transformation, however, had remained elusive. Previously reported chiral Brønsted acids were unsuccessful due to either lack of catalytic activity (e.g. chiral phosphoric acids, IDP) or inability to differentiate between substrate and product aldehydes (DSI). In contrast, IDPi 3j cleanly converted benzaldehyde (1c) and the simple TES enolate of acetaldehyde (37a) into aldol $\mathbf{3 8 c}$ in very high yield (95\%) and a remarkable e.r. of 99:1. [51]

Substituted benzaldehydes, such as o-tolualdehyde and $m$-anisaldehyde were well-tolerated substrates and provided the single addition products with TES enolate 37 a or TBS enolate $\mathbf{3 7 b}$ in similarly high yields and enantioselectivities (Table 10, Entries 1-2). Intriguingly, even aliphatic aldehydes were efficiently transformed and furnished the desired single aldolization products in high yields and good to excellent e.r. (Entries 3-6). ${ }^{[51]}$ 
Table 10. Selected examples of the substrate scope of the IDPi-catalyzed Mukaiyama aldol reaction with acetaldehyde enolsilanes.

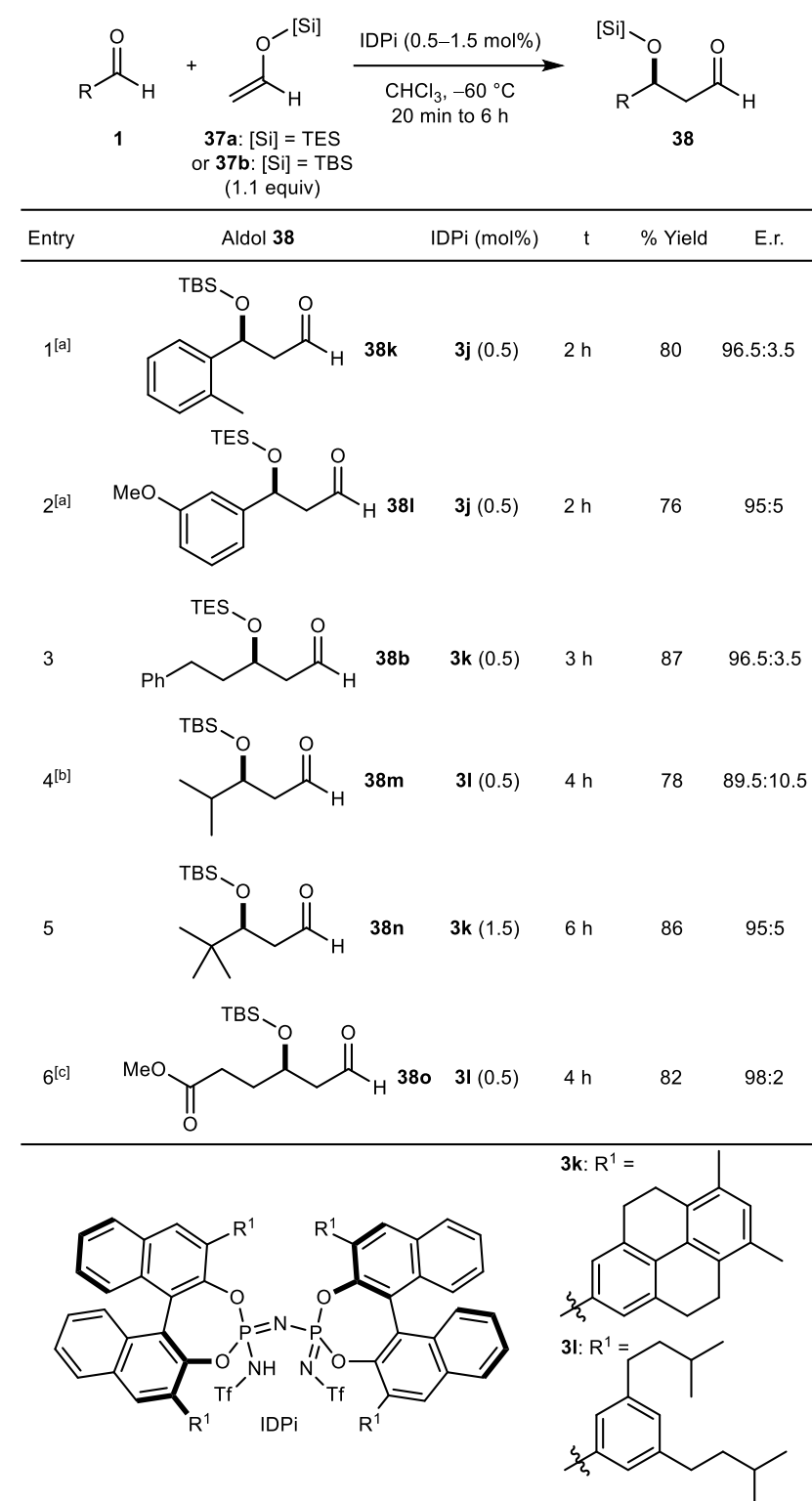

[a] Reactions conducted in $\mathrm{CHCl}_{3} / n$-hexane $(5: 4)$ at $-78{ }^{\circ} \mathrm{C}$. [b] Using 1.2 equiv of enolsilane $\mathbf{3 7 b}$. [c] Using 1.4 equiv of enolsilane $37 \mathrm{~b}$

The authors described a strong influence of the size of the silyl group present in both enolate $\mathbf{3 7}$ and aldol $\mathbf{3 8}$ on the proneness of the aldol product to react further under the reaction conditions. Specifically, benzaldehyde (1c) reacted with each 1.5 equivalents of TES enolate $37 \mathbf{a}$ and TMS enolate $37 \mathrm{c}$ in the presence of IDPi $3 \mathrm{~m}$ to afford the corresponding TES (38c) and TMS (38p) aldols in 99 and $62 \%$ yield, respectively (Scheme 3).

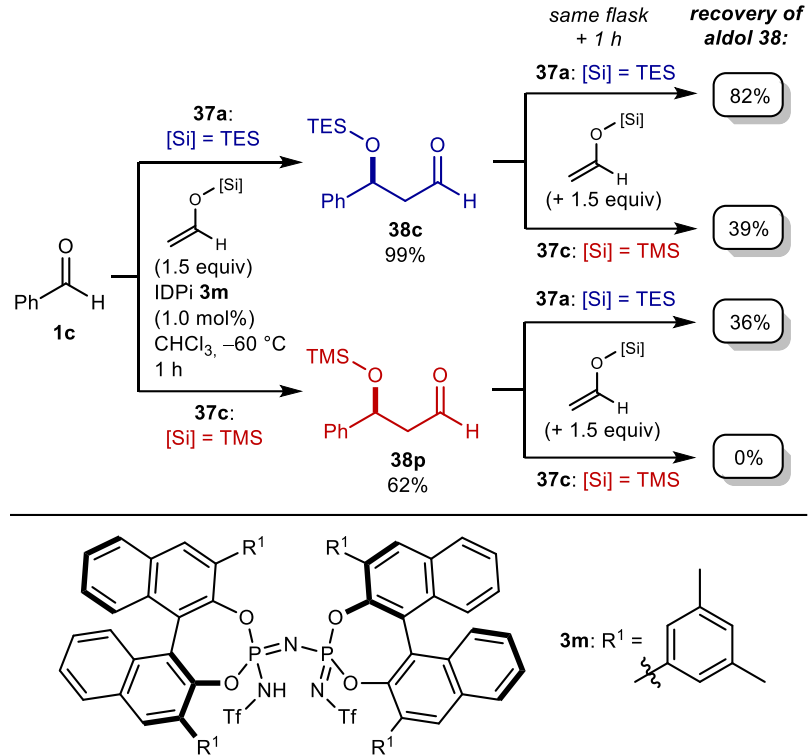

Scheme 3. Influence of the size of the silyl group on the IDPi-catalyzed Mukaiyama aldol reaction with acetaldehyde enolates.

Exposure to a further 1.5 equivalents of either enolsilane $(37 \mathrm{a}$ or $37 \mathrm{c}$ ) for an additional $1 \mathrm{~h}$ resulted in vastly different levels of consumption of aldols 38, depending on the silyl group combinations. The extremes herein are marked by the combinations of TES/TES and TMS/TMS. While the former still gave rise to aldol $38 \mathrm{c}$ in a yield of $82 \%$, the latter resulted in the complete consumption of transiently generated aldol $38 p$, indicating a primarily steric discrimination between substrate and product aldehydes, enabled by the confined space of the catalyst's active site (Figure 5). ${ }^{[51]}$

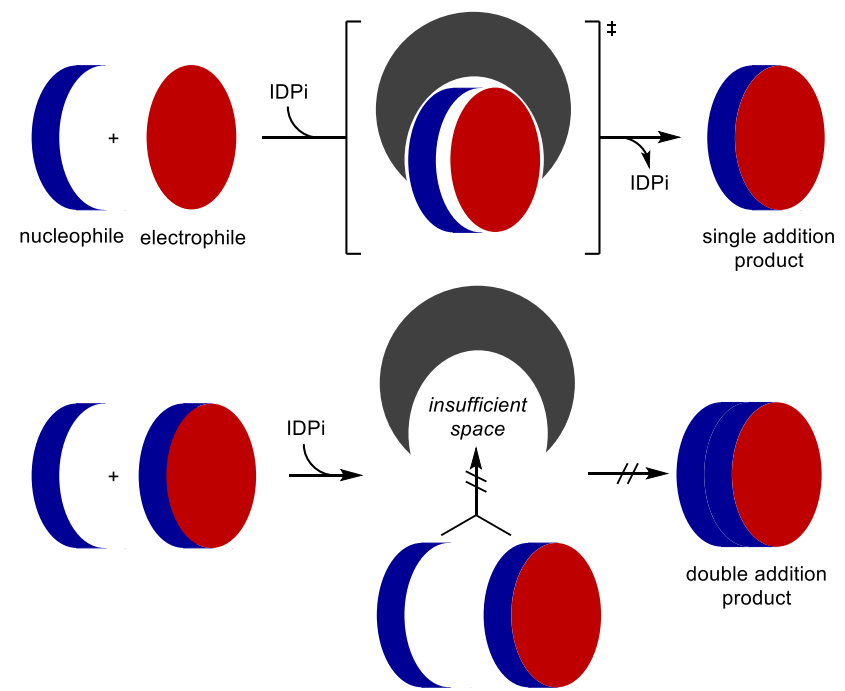

Figure 5. Schematic depiction of the origin of the substrate-product discrimination by the catalyst. 


\section{IDPi in Brønsted Acid Catalysis}

The design of ever more acidic chiral Brønsted acids for both enantioselective Brønsted and "silylium" Lewis acid catalysis has been key to expanding the scope of substrate classes to more challenging and less basic ones. While phosphoric acids like $\operatorname{TRIP}\left(39 ; \mathrm{p} K_{\mathrm{a}}=13.6 \text { in } \mathrm{MeCN}\right)^{[14]}$ are widely limited to readily activated imines, ${ }^{[53]}$ the significantly more acidic DSIs $\left(\mathrm{p} K_{\mathrm{a}}(\mathbf{2 b})=8.4\right.$ in $\mathrm{MeCN}$; cf. $\mathrm{p} K_{\mathrm{a}}(p-\mathrm{TsOH})=8.5$ in $\mathrm{MeCN}$; Figure 6$)^{[14]}$ expanded the boundaries to the activation of aldehydes for numerous $\mathrm{C}-\mathrm{C}$ bond-forming addition reactions. ${ }^{[15]}$

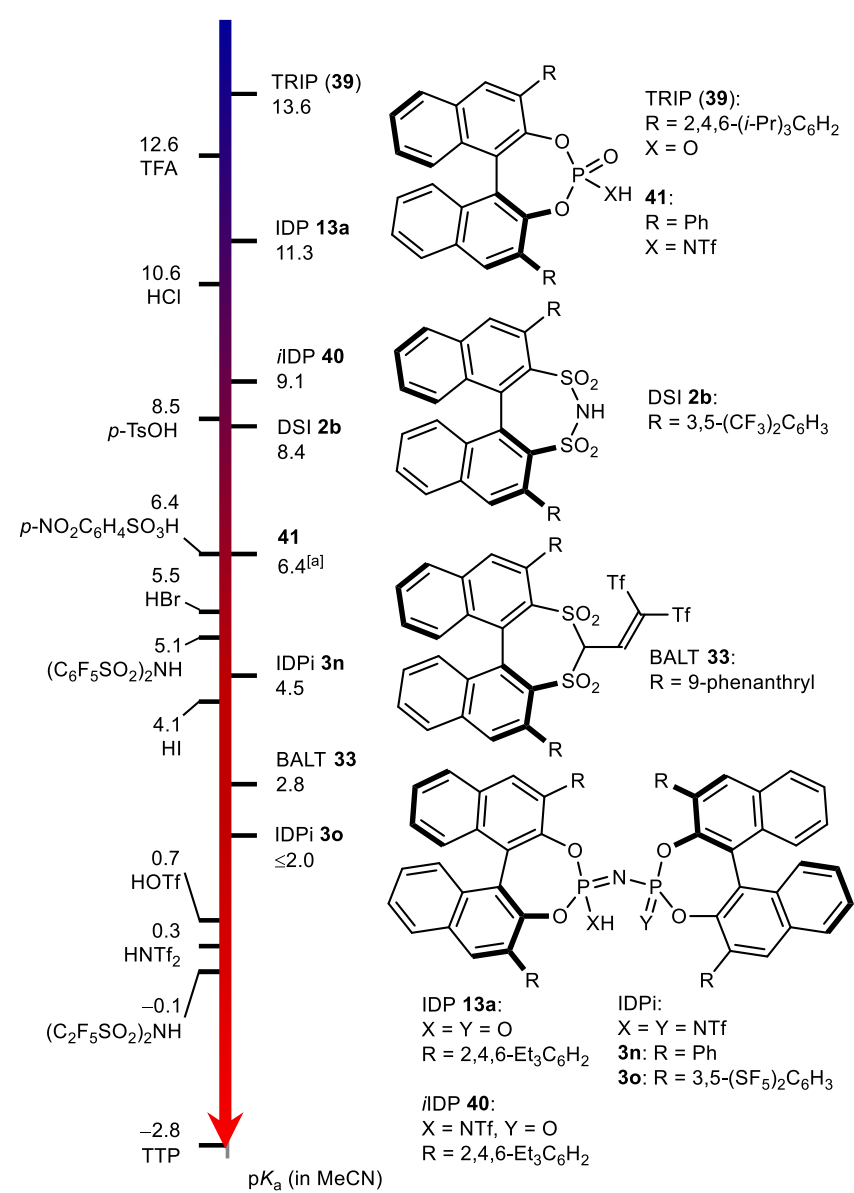

Figure 6. Experimental $\mathrm{p} K_{\mathrm{a}}$ values of chiral and achiral Brønsted acids in MeCN. ${ }^{[14]}$ TTP $=$ 1,1,3,3-tetratriflylpropene. [a] Ref. 54.

For the addition of particularly unreactive nucleophiles such as allyltrimethylsilane (cf. Chapter 1.1), however, as well as the activation of even less basic substrates, including olefins, ${ }^{[55]}$ this catalyst class had still proven insufficiently active, resulting either in low substrate conversion and/or in undesired side-reactions driven by the Brønsted basicity of the counteranion. ${ }^{[43,28]}$ By comparison, the basicities of the recently reported binaphthyl-allyl-tetrasulfones (BALT 33; $\mathrm{pK}$ $=2.8$ in MeCN) and IDPis ( $K_{a}(3 n)=4.5, p K_{a}(30) \leq 2.0$ in $\mathrm{MeCN}$ ) are profoundly reduced, ${ }^{[14]}$ allowing the selective conversion of such unreactive substrates as $\alpha, \beta$-unsaturated esters, ${ }^{[37]}$ readily enolizable ketones ${ }^{[43]}$ and even simple olefins. ${ }^{[55]}$ The following section describes applications of IDPis for challenging Brønsted acid-catalyzed transformations.

\subsection{Catalytic Asymmetric Vinylogous Prins Cyclization: A Highly Diastereo- and Enantioselective Entry to Tetrahydrofurans}

Intramolecular reactions featuring the nucleophilic capture of oxonium ions by alkenes are valuable tools in the construction of cyclic ethers, such as tetrahydropyrans (THPs) and tetrahydrofurans (THFs). These ene and Prins reactions have been divided into three classes, according to the connectivity of the carbonyl oxygen and the alkene. ${ }^{[56]}$ Specifically, in type III Prins reactions, in which the side chain bearing the alkene is tethered to the oxonium ion oxygen, cyclic ethers originate from carbocationic intermediates. The nature and stability of such intermediates, and therefore the relative energies of the transition states (TS), dictate the outcome of the cyclization to afford 5- or 6-membered rings when $\gamma, \delta$-unsaturated oxonium ions are involved. In this context, the acid-catalyzed Prins cyclization of homoallylic alcohols with aldehydes predominantly delivers THP products. ${ }^{[57]}$ However, the presence of an additional double bond in dienols of type 42a allowed the List group to access the less preferred THF ethers, owing to the supplementary stabilization imparted by the allylic cation (Scheme 4). ${ }^{[58]}$ While catalytic asymmetric Prins cyclizations to yield THPs have recently been reported, ${ }^{[59]}$ an additional complication associated with the synthesis of THF rings is the more challenging discrimination between the two possible transition states leading to different diastereomers. ${ }^{[60]}$

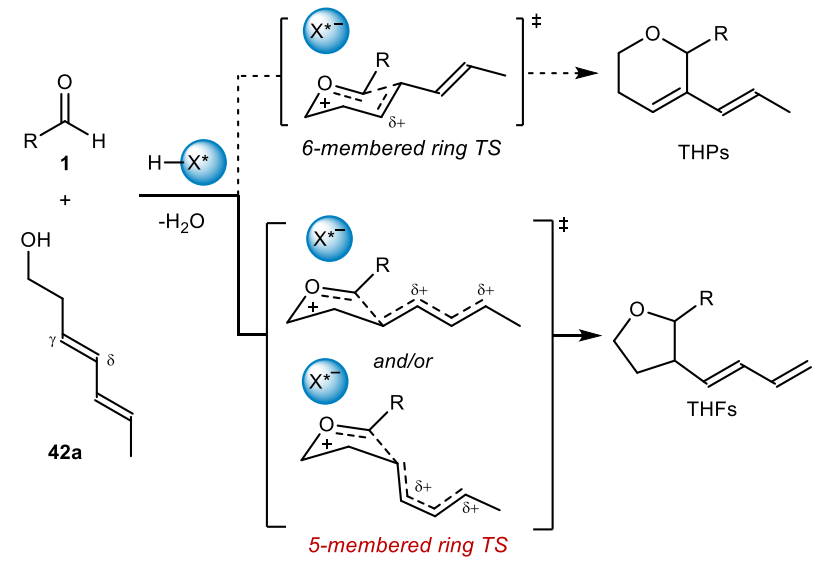

Scheme 4. Prins cyclization of dienol $\mathbf{4 2}$ with aldehydes (1).

Nonetheless, under Brønsted acidic conditions enabled by IDP, THF products could be accessed with high diastereoand enantioselectivities when various (hetero)aromatic aldehydes were subjected to the optimized reaction conditions (Table 11, Entries 1-3). Quaternary stereocenters could also be assembled, with only slightly diminished enantioselectivity (Entry 4). ${ }^{[58]}$ To this point, the limitation of the methodology resided in the inability to handle simple aliphatic aldehydes. Indeed, unreactive acetals were exclusively produced under the catalysis operated by IDP catalysts. 
Table 11. Selected examples for the diastereo- and enantioselective synthesis of THFs using aromatic and aliphatic aldehydes.
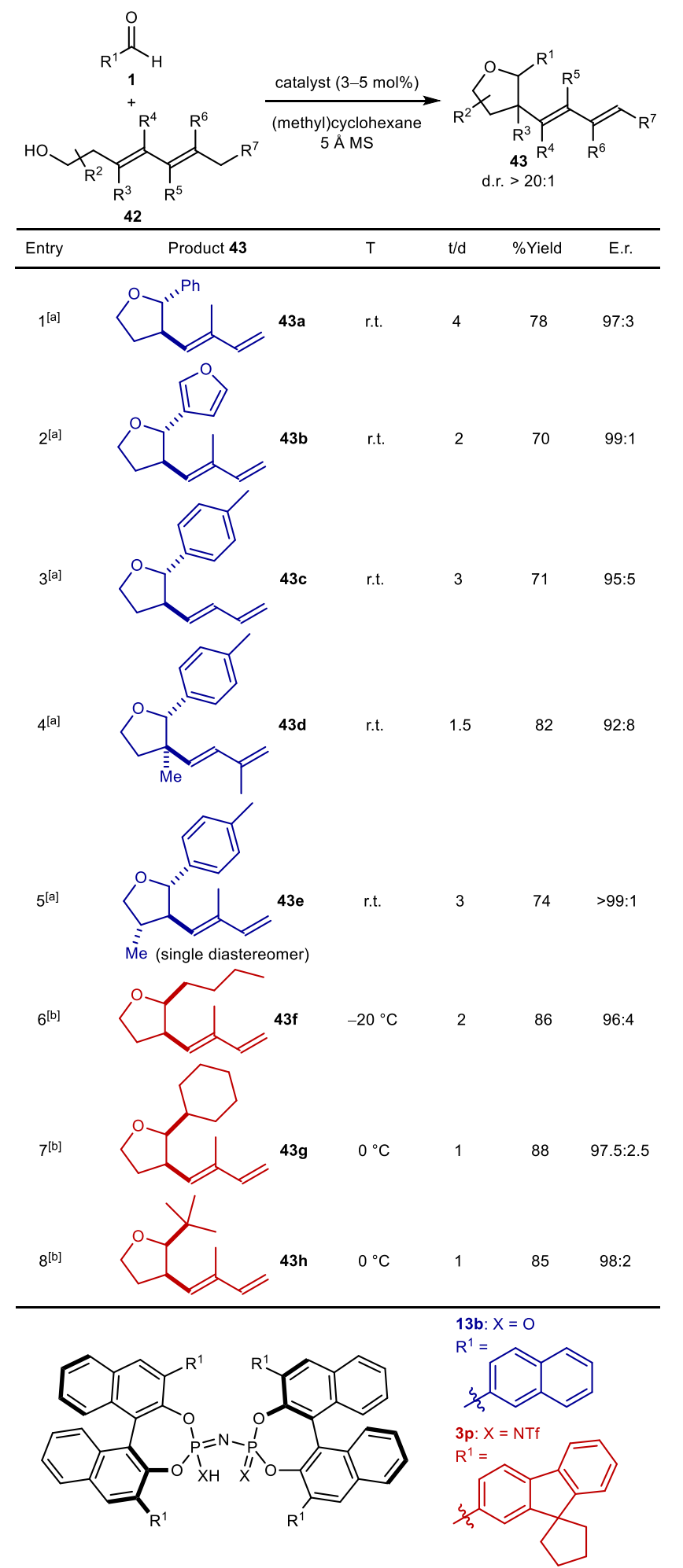

[a] Using IDP 13b. [b] Using IDPi 3p

In contrast, IDPi catalysts displayed excellent reactivity to afford the desired 2,3-disubstituted THF products from aliphatic aldehydes owed to the enhanced Brønsted acidity of this catalyst class, in remarkably high diastereo- and enantioselectivities (Entries 6-8). ${ }^{[58]}$

\subsection{Catalytic Asymmetric [4+2]-Cycloaddition of Dienes with Aldehydes}

In the previous chapter, the conjugated diene moiety of nucleophiles 42 engaged in intramolecular $\mathrm{C}-\mathrm{C}$ bond formation upon condensation of the hydroxy group with an aldehyde. The absence of this "hydroxy handle" results in orthogonal reactivity, where a $\mathrm{C}-\mathrm{C}$ bond is formed between the 1,3-diene and the activated carbonyl unit in an intermolecular fashion, as well as a simultaneous or subsequent $\mathrm{C}-\mathrm{O}$ bond formation, giving rise to dihydropyrans, the (formal) products of a hetero-Diels-Alder reaction.

Since the first report by Gresham and Steadman in 1949, [61] the [4+2]-cycloaddition of dienes with aldehydes gained influence over decades for its efficiency and synthetic utility in the quick assembly of pyran substructures. Furthermore, the possibility to generate contiguous stereogenic centers has encouraged the development of asymmetric versions, granting access to valuable optically-active compounds. ${ }^{[62]}$ To control the absolute configuration of the product, strategies relying on both chiral auxiliaries and catalysts were developed.

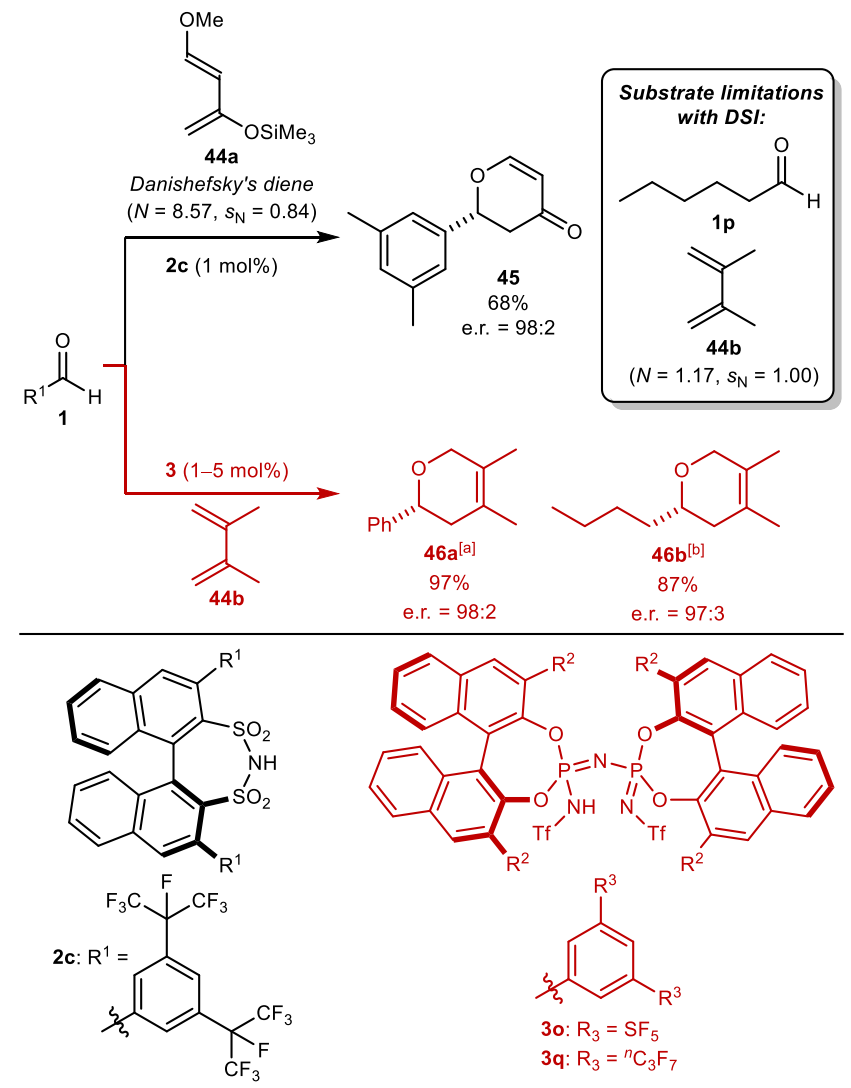

Scheme 5. Reactivity comparison between DSI and IDPi catalysts. [a] Using IDPi 3o. [b] Using IDPi 3q.

The engagement of simpler feedstocks in this reaction has found its main obstacle in the large energy gap between the involved frontier orbitals of less activated species. ${ }^{[64]}$ 
Table 12. Selected examples of the [4+2]-cycloaddition reaction of simple dienes with aromatic and aliphatic aldehydes.

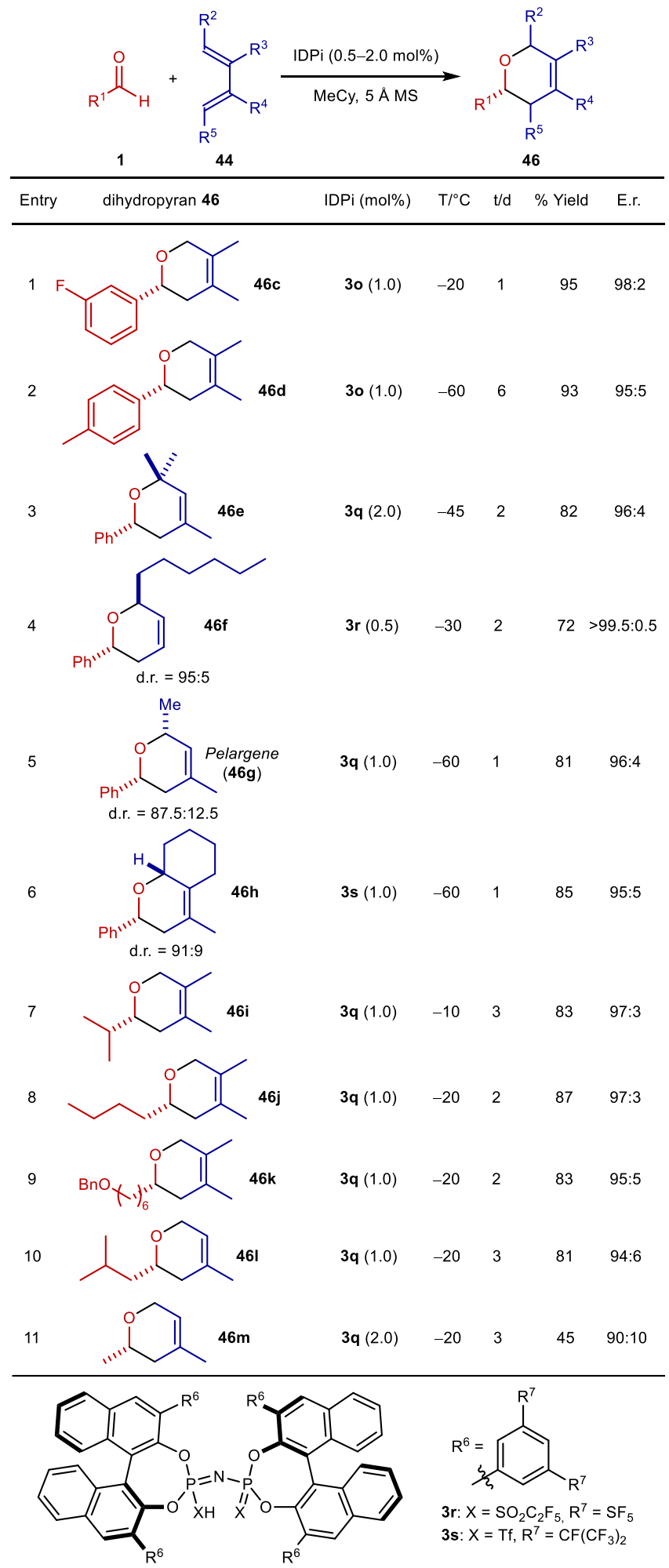

The Aggarwal group has shown that the strong Brønsted acid $\mathrm{TfOH}$ is capable of catalyzing the reaction of aromatic aldehydes with simple dienes such as isoprene. ${ }^{[65]}$ List and coworkers recently found that IDPi catalysts possess appropriate features to catalyze this transformation with high reactivity and selectivity. ${ }^{[66]}$

The superior acidity and enhanced confinement of IDPi enabled simple 2,3-dimethyl-1,3-butadiene

$(44 b$; nucleophilicity parameter $\left.N=1.17, S_{N}=1.00\right)^{[67]}$ to react with aromatic and even simple aliphatic aldehydes that proved inaccessible with $\mathrm{TfOH}$ (Scheme 5), thereby overcoming the severe limitations of DSIs to aromatic aldehydes and highly reactive dienes (e.g. Danishefsky diene (44a): $N=8.57, s_{N}=$ 0.84). ${ }^{[63 b, 68]}$ Along with the reaction of various aromatic and aliphatic aldehydes with 2,3-dimethyl-1,3-butadiene (44b; Table 12, Entries 1, 2 and 7-9), examples displaying the reactivity of other simple dienes with a range of aldehydes were also reported (Entries 3-6 and 10, 11). ${ }^{66]}$

To validate the practicality of the methodology, gram scale experiments were performed. With a catalyst loading as low as $0.2 \mathrm{~mol} \%$, benzaldehyde (1c) could be reacted with 2,3-dimethyl-1,3-butadiene (44b) to afford the desired dihydropyran 46a in excellent yield and enantioselectivity. Moreover, $97 \%$ of the catalyst could be recovered (Scheme 6a). Similarly, the commercialized fragrance Verdirosa (46n) could be prepared with high enantopurity, and subsequently be reduced to Doremox (47), an odorant with a rosy note (Scheme 6b).

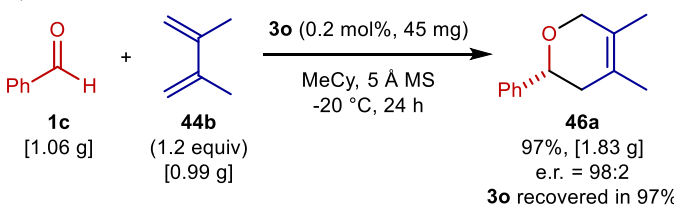

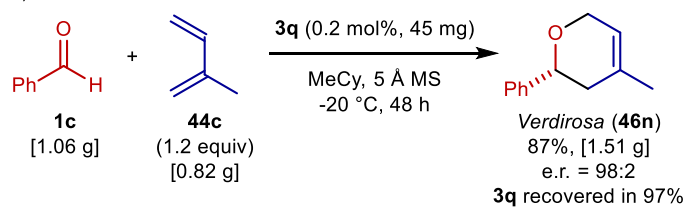

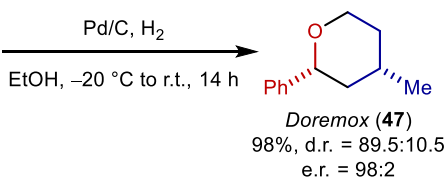

Scheme 6. Preparative scale experiments and synthesis of valuable small molecules.

\subsection{Hydroalkoxylation of Simple Olefins}

The employment of unactivated 1,3-dienes as nucleophiles in asymmetric Prins cyclizations (cf. Chapter 2.1) and [4+2]cycloadditions (cf. Chapter 2.2) has faced vast difficulties that could only be addressed with a catalyst class as acidic as IDPi. A perhaps even greater challenge has been the application of simple olefins as electrophiles in hydrofunctionalizations, owed to their inherent low Brønsted basicity. Yet, the intrinsic simplicity, perfect atom economy and the abundant substrate availability renders such hydrofunctionalizations highly desirable. ${ }^{[69]}$ Despite all advances, enantioselective Markovnikov, as well as anti-Markovnikov hydroalkoxylations, had remained an unsolved problem. Previously reported photochemical and transition metal-based approaches achieved only modest enantioselectivities and in the case of intramolecular variants were limited to substrates of enhanced reactivity, ${ }^{[70]}$ e.g. through application of the Thorpe-Ingoldeffect. ${ }^{[11]}$ While enzymes efficiently catalyze transformations that require the protonation of unactivated olefins, such as the cyclization of squalene to hopene, ${ }^{[72]}$ it was not until recently 
that an enzymatic enantioselective hydroalkoxylation as part of the biosynthesis of the fungal natural product herqueinone was reported. ${ }^{[73]}$ In contrast, the employment of unactivated olefins as electrophiles in asymmetric hydroalkoxylations has remained elusive in Bronsted acid catalysis. With the intramolecular hydroalkoxylation of enol 48 a to produce THF $49 \mathrm{a}$ as a model reaction, the List group demonstrated how DSI $\mathbf{2 b}$ proved just active enough to afford moderate yields of the targeted compound, albeit in almost racemic form (Table 13).

Table 13. Performance of different classes of chiral Brønsted acids in the hydroalkoxylation of enol $48 \mathrm{a}$.

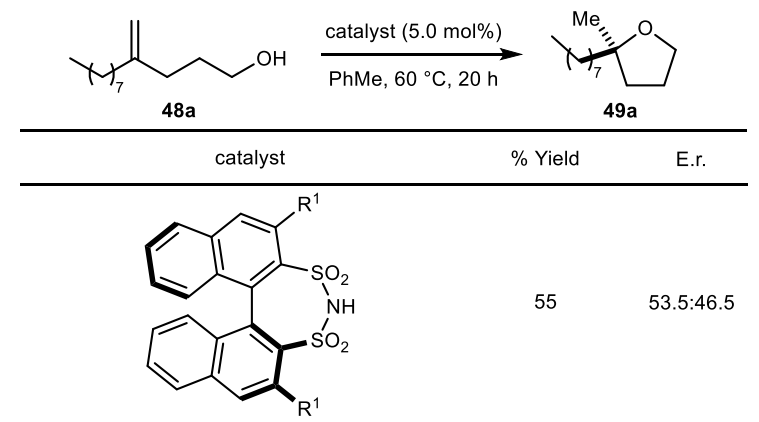

2b: $\mathrm{R}^{1}=3,5-\left(\mathrm{CF}_{3}\right)_{2} \mathrm{C}_{6} \mathrm{H}_{3}$

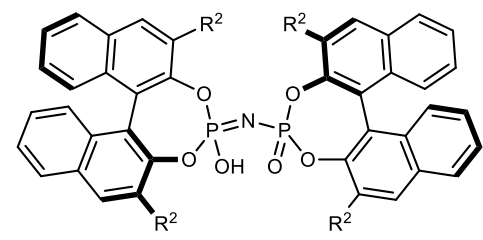

n.d. ${ }^{[a]}$

13a: $R^{2}=2,4,6-\mathrm{Et}_{3} \mathrm{C}_{6} \mathrm{H}_{2}$

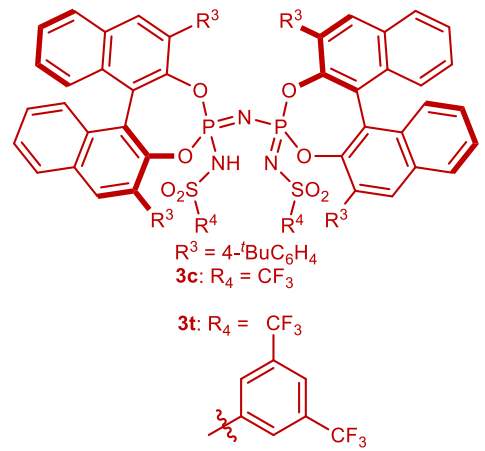

[a] THF 49a not detected. [b] Reaction conducted in cyclohexane.

The less acidic IDP 13a, however, was catalytically inactive in this process. Intriguingly, IDPi $3 c$ exhibited high catalytic activity toward the desired hydroalkoxylation, providing THF 49a in high yield and good enantioselectivity. ${ }^{[55]}$ Upon changing the solvent to cyclohexane $(\mathrm{CyH})$ and replacing the triflyl groups of the core by the bulky 3,5-bis(trifluoromethyl)benzenesulfonyl groups (IDPi $3 \mathbf{t}$ ), the enantioselectivity was improved even further, without reduction of catalytic activity and yield. A variety of functionalized and unfunctionalized alkenols were successfully converted under the optimized reaction conditions, providing the desired THFs in good yields and excellent enantioselectivities (Table 14, Entries 1-4). ${ }^{[55]}$
Table 14. Selected examples of the substrate scope.
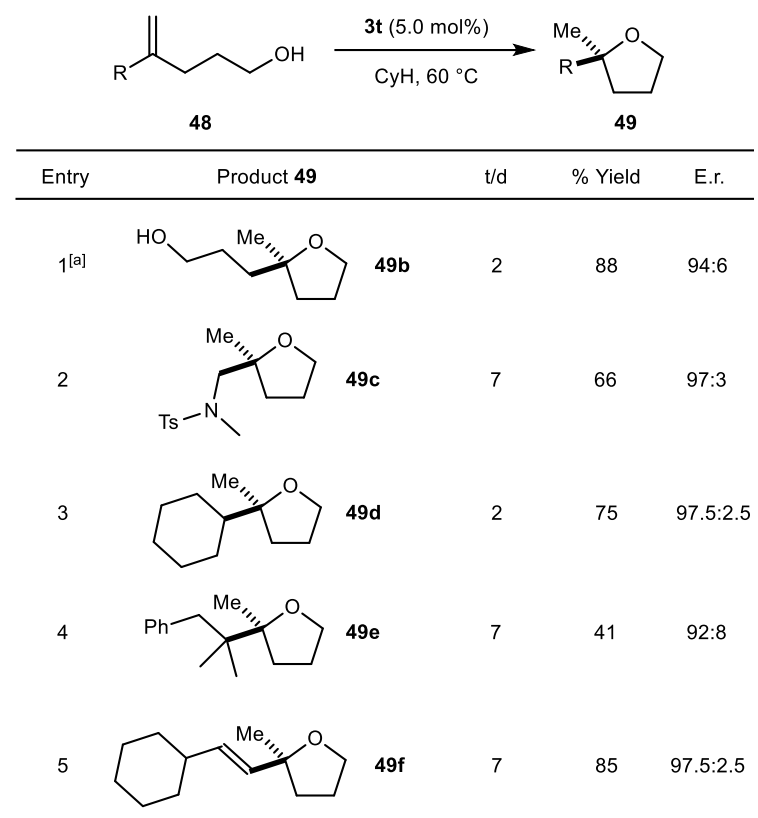

6

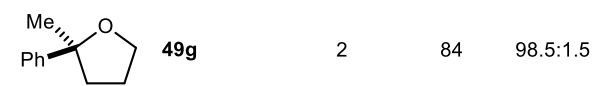

7

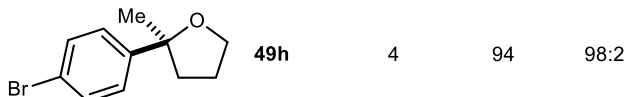

8<smiles>CC1(C)CCCCO1</smiles>

50

$70 \quad 92.5: 7.5$

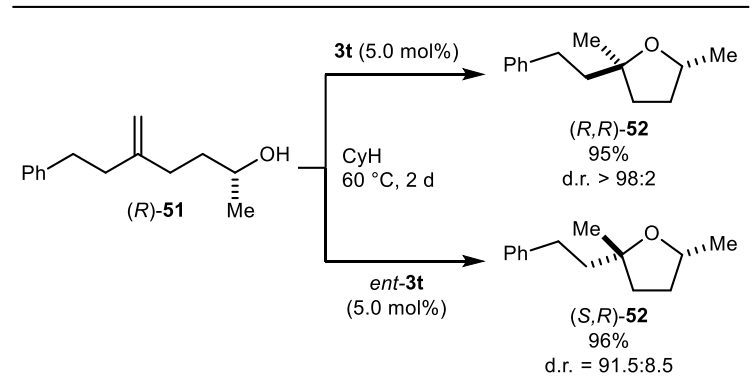

[a] Reaction conducted in 1,2-dichloroethane/cyclohexane $=1: 1$.

Diene- and styrene-derived substrates were also well tolerated (Entries 5-7), and THP 50 could be accessed from the corresponding homologated alkenol substrate in $70 \%$ yield and only slightly diminished enantioselectivity (entry 8). Moreover, excellent catalyst-controlled diastereoselectivities were observed in the hydroalkoxylation of chiral alkenol $(R)$ 51 bearing a stereogenic center in the $\alpha$-position of the reacting hydroxy group, using either IDPi 3 t or its enantiomer ent-3t. 
Based on DFT studies and a Hammett analysis, the reaction is proposed to comprise an asynchronous concerted mechanism, which is initiated by the protonation of the olefin, followed by the $\mathrm{C}-\mathrm{O}$ bond formation, deprotonation and release of the product (Scheme 7a). This scenario is in line with experimental results, showing no reactivity with the regioisomeric substrates $(E)$ - and (Z)-53 and vastly different reactivity and enantioselectivity in the case of diol 54 as alternate cyclization precursors (Scheme 7b).

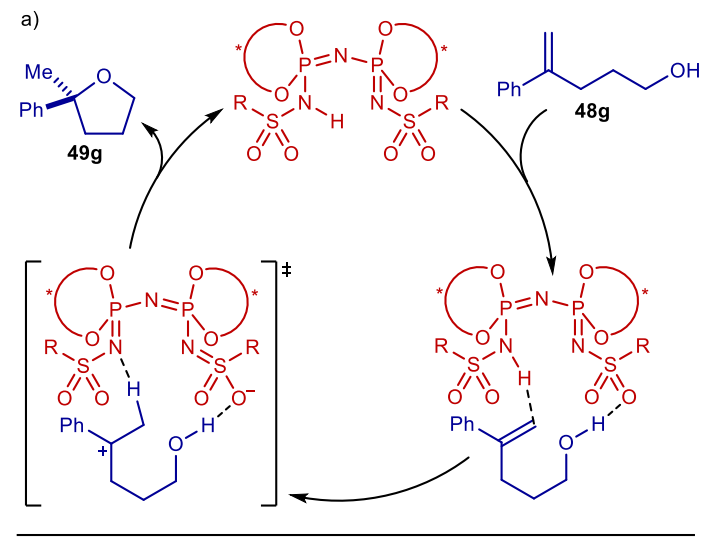

b)

$$
\text { substrate } \underset{\mathrm{CyH}, 60^{\circ} \mathrm{C}, 2 \mathrm{~d}}{\stackrel{3 \mathrm{t}(5.0 \mathrm{~mol} \%)}{\longrightarrow}} \stackrel{\mathrm{Ph}}{\stackrel{\mathrm{Me}}{\longrightarrow}} \underset{49 \mathrm{~g}}{\longrightarrow}
$$

$$
\text { (Z)-53 }
$$

Scheme 7. Mechanistic studies. a) Proposed catalytic cycle. b) Performances of alternate cyclization precursors 53 and 54. n.d. = not detected.

\section{Conclusion and Outlook}

Imidodiphosphorimidates (IDPis) have opened doors to unprecedented reactivities in catalysis, while providing outstanding stereocontrol in a series of challenging inter- and intramolecular $\mathrm{C}-\mathrm{C}$ and $\mathrm{C}-\mathrm{O}$ bond-forming reactions. Small organic molecules such as proline are capable of catalyzing transformations with high enantioselectivities through the presence of covalent and strong non-covalent (H-bonding) interactions with the reacting substrates. ${ }^{[74]}$ In contrast, IDPis, mimicking enzymes, effect excellent enantiofacial discrimination through the confined chiral microenvironment of their substrate binding sites (Figure 7).

The immense potential of IDPi catalysts has been amply illustrated in only a short period of time, and various further applications and mechanistic insights can be expected in the future.
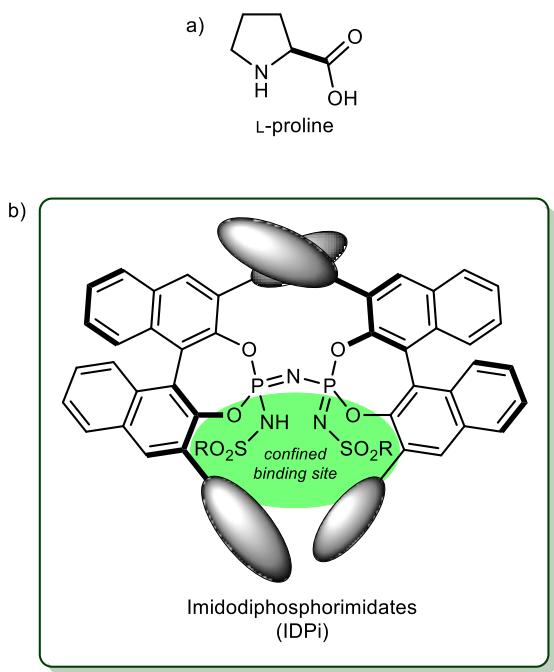

c)

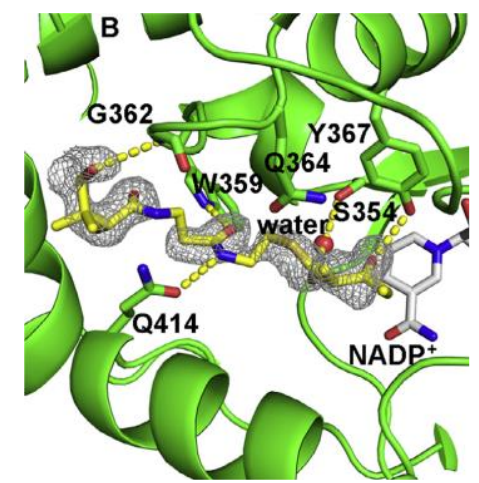

Figure 7. IDPi (b) as small "artificial enzymes" between small organocatalysts such as proline (a) and enzymes (c). ${ }^{[75]}$

Keywords: organocatalysis • Brønsted acids • Lewis acids • enantioselective catalysis $\cdot A C D C \cdot$ silylium ions

[1] a) M. Schmeißer, P. Sartori, B. Lippsmeier, Chem. Ber. 1970, 103, 868-879. b) H. W. Roesky, H. H. Giere, Z. Naturforsch. 1970, 25 b, 773-776.

[2] U. Wannagat, W. Liehr, Angew. Chem. 1957, 69, 783-784.

[3] H. Vorbrüggen, K. Krolikiewicz, Angew. Chem. Int. Ed. 1975, 14, 421-422.

[4] T. Tsunoda, M. Suzuki, R. Noyori, Tetrahedron Lett. 1980, 21, 71-74.

[5] B. Mathieu, L. Ghosez, Tetrahedron Lett. 1997, 38, 5497-5500.

[6] A. Ishii, O. Kotera, T. Saeki, K. Mikami, Synlett 1997, 1145-1146.

[7] J. Foropoulos, D. D. Desmarteau, Inorg. Chem. 1984, 23, 3720-3723.

[8] a) K. Ishihara, Y. Hiraiwa, H. Yamamoto, Synlett 2001, 1851-1854. b) W. Gati, H. Yamamoto, Acc. Chem. Res. 2016, 49, 1757-1768.

[9] a) E. M. Carreira, R. A. Singer, Tetrahedron Lett. 1994, 35, 4323-4326. b) T. K. Hollis, B. Bosnich, J. Am. Chem. Soc. 1995, 28, 4570-4581.

[10] S. Mayer, B. List, Angew. Chem. Int. Ed. 2006, 45, 4193-4195.

[11] D. Uraguchi, M. Terada, J. Am. Chem. Soc. 2004, 126, 5356-5357.

[12] T. Akiyama, J. Itoh, K. Yokota, K. Fuchibe, Angew. Chem. Int. Ed. 2004, 43, 1566-1568.

[13] P. García-García, F. Lay, P. García-García, C. Rabalakos, B. List, Angew. Chem. Int. Ed. 2009, 48, 4363-4366.

[14] A manuscript including all experimental $p K_{a}$ values discussed in this minireview is currently in preparation.

[15] T. James, M. van Gemmeren, B. List, Chem. Rev. 2015, 115, 9388-9409.

[16] I. Čorić, B. List, Nature 2012, 483, 315-319.

[17] a) S. Liao, I. Čorić, Q. Wang, B. List, J. Am. Chem. Soc. 2012, 134, 1076510768. b) J. H. Kim, I. Čorić, S. Vellalath, B. List, Angew. Chem. Int. Ed. 2013, 52, 4474-4477. c) J. H. Kim, I. Čorić, C. Palumbo, B. List, J. Am. Chem. Soc. 2015, 137, 1778-1781. d) J. H. Kim, A. Tap, L. Liu, B. List, Synlett 2017, 28, 333-336. 
[18] S. Lee, P. S. J. Kaib, B. List, J. Am. Chem. Soc. 2017, 139, 2156-2159.

[19] L. M. Yagupolskii, V. N. Petrik, N. V. Kondratenko, L. Sooväli, I. Kaljurand, I. Leito, I. A. Koppel, J. Chem. Soc. Perkin Trans. 2 2002, 1950-1955.

[20] a) S. E. Denmark, J. Fu, Chem. Rev. 2003, 103, 2763-2793. b) M. Yus, C. Gonz, F. Foubelo, Chem. Rev. 2011, 111, 7774-7854

[21] T. Herold, R. W. Hoffmann, Angew. Chem. Int. Ed. 1978, 17, 768-769.

[22] For a selection of chiral allylating agents, see: I. S. Kim, M.-Y. Ngai, M. J. Krische, J. Am. Chem. Soc. 2008, 130, 14891-14899.

[23] A. Hosomi, H. Sakurai, Tetrahedron Lett. 1976, 17, 1295-1298.

[24] Nucleophilicity parameter $N=1.68$, nucleophile-specific sensitivity parameter $s_{\mathrm{N}}=1.00$ (J. Ammer, C. Nolte, H. Mayr, J. Am. Chem. Soc. 2012, 134, 13902-13911), cf. allyltri( $n$-butyl)tin: $N=5.46, s_{N}=0.89$ (Ref. 67).

[25] a) K. Furuta, M. Mouri, H. Yamamoto, Synlett 1991, 561-562. b) K. Ishihara, M. Mouri, Q. Gao, T. Maruyama, K. Furuta, H. Yamamoto, J. Am. Chem. Soc. 1993, 115, 11490-11495.

[26] D. R. Gauthier Jr., E. M. Carreira, Angew. Chem. Int. Ed. 1996, 35, 2363-2365.

[27] Methallyltrimethylsilane: $N=4.41, s_{N}=0.96$ (J. Ammer, C. Nolte, H. Mayr, J. Am. Chem. Soc. 2012, 134, 13902-13911).

[28] M. Mahlau, P. García-García, B. List, Chem. A Eur. J. 2012, 18, 16283-16287.

[29] P. S. J. Kaib, L. Schreyer, S. Lee, R. Properzi, B. List, Angew. Chem. Int. Ed. 2016, 55, 13200-13203.

[30] a) L. Krasnova, C.-H. Wong, Annu. Rev. Biochem. 2016, 85, 599-630. b) M. M. Faul, B. E. Huff, Chem. Rev. 2000, 100, 2407-2473. c) E. J. Kang, E. Lee, Chem. Rev. 2005, 105, 4348-4378.

[31] Selected examples of previously reported addition reactions to cyclic oxocarbenium ions/ion intermediates: a) M. Braun, W. Kotter, Angew. Chem. Int. Ed. 2004, 43, 514-517. b) S. E. Reisman, A. G. Doyle, E. N. Jacobsen, J. Am. Chem. Soc. 2008, 130, 7198-7199. c) P. N. Moquist, T. Kodama, S. E. Schaus, Angew. Chem. Int. Ed. 2010 49, 7096-7100. d) P. Maity, H. D. Srinivas, M. P. Watson, J. Am. Chem. Soc. 2011, 133, 17142-17145. e) Z. Yang, Y. He, F. D. Toste, J. Am. Chem. Soc. 2016, 138, 9775-9778.

[32] S. Lee, H. Y. Bae, B. List, Angew. Chem. Int. Ed. 2018, 57, 12162-12166.

[33] D. S. Allgäuer, H. Jangra, H. Asahara, Z. Li, Q. Chen, H. Zipse, A. R. Ofial, H. Mayr, J. Am. Chem. Soc. 2017, 139, 13318-13329.

[34] a) E. M. Carreira, L. Kvaerno, Classics in Stereoselective Synthesis, Wiley, Hoboken, 2009. b) K. Hermann, H. Wynberg, J. Org. Chem. 1979, 44 2238-2244. c) M. Sawamura, H. Hamashima, Y. Ito, J. Am. Chem. Soc. 1992, 114, 8295-8296. d) T. Arai, H. Sasai, K. Aoe, K. Okamura, T. Date, M. Shibasaki, Angew. Chem. Int. Ed. 1996, 35, 104-106. e) S. P. Brown, N. C. Goodwin, D. W. C. MacMillan, J. Am. Chem. Soc. 2003, 125, 1192 1194. f) Y. Zhang, W. Wang, Catal. Sci. Technol. 2012, 2, 42-53. g) C. Hui, F. Pu, J. Xu, Chem. Eur. J. 2017, 23, 4023-4036.

[35] a) J. Y. Kang, R. G. Carter, Org. Lett. 2012, 14, 3178-3181. b) B. M. Trost, K. Hirano, Org. Lett. 2012, 14, 2446-2449.

[36] a) G. Desimoni, G. Faita, P. Quadrelli, Chem. Rev. 2015, 115, 9922-9980. b) D. Monge, H. Jiang, Y. Alvarez-Casao, Chem. Eur. J. 2015, 21 4494-4504. c) N. Kumagai, M. Shibasaki, Chem. Eur. J. 2016, 22, 1519215200.

[37] T. Gatzenmeier, M. van Gemmeren, Y. Xie, D. Höfler, M. Leutzsch, B. List, Science 2016, 351, 949-952.

[38] T. Gatzenmeier, P. S. J. Kaib, J. B. Lingnau, R. Goddard, B. List, Angew. Chem. Int. Ed. 2018, 57, 2464-2468.

[39] a) R. Mahrwald, Modern Aldol Reactions, Wiley, Weinheim, 2004. b) R. Mahrwald, Modern Methods in Stereoselective Aldol Reactions, Wiley, Weinheim, 2013. c) M. Frías, W. Cieślik, A. Fraile, A. Rosado-Abón, A. F. Garrido-Castro, F. Yuste, J. Alemán, Chem. Eur. J. 2018, 24, 10906-10933. d) S. Hosokawa, Tetrahedron Lett. 2018, 59, 77-88.

[40] M. Hatano, E. Takagi, K. Ishihara, Org. Lett. 2007, 9, 4527-4530.

[41] a) S. E. Denmark, Y. Fan, J. Am. Chem. Soc. 2002, 124, 4233-4235. b) S. E. Denmark, Y. Fan, M. D. Eastgate, J. Org. Chem. 2005, 70, 5235-5248.

[42] K. Oisaki, D. Zhao, M. Kanai, M. Shibasaki, J. Am. Chem. Soc. 2006, 128, 7164-7165.

[43] H. Y. Bae, D. Höfler, P. S. J. Kaib, P. Kasaplar, C. K. De, A. Döhring, S. Lee, K. Kaupmees, I. Leito, B. List, Nat. Chem. 2018, 10, 888-894.

[44] S. E. Denmark, S. K. Ghosh, Angew. Chem. Int. Ed. 2001, 40, 4759-4762.

[45] E. J. Corey, C.-M. Yu, S. S. Kim, J. Am. Chem. Soc. 1989, 111, 5495-5496.
[46] E. M. Carreira, R. A. Singer, W. Lee, J. Am. Chem. Soc. 1994, 116, 88378838.

[47] T. D. Machajewski, C.-H. Wong, Angew. Chem. Int. Ed. 2000, 39, 1352-1374.

[48] S. E. Denmark, S. K. Ghosh, Angew. Chem. Int. Ed. 2001, 40, 4759-4762.

[49] a) A. B. Northrup, D. W. C. MacMillan, J. Am. Chem. Soc. 2002, 124, 67986799. b) N. Mase, F. Tanaka, C. F. Barbas III, Angew. Chem. Int. Ed. 2004, 43, 2420-2423. c) T. Kano, Y. Yamaguchi, Y. Tanaka, K. Maruoka, Angew. Chem. Int. Ed. 2007, 46, 1738-1740. d) M. Markert, U. Scheffler, R Mahrwald, J. Am. Chem. Soc. 2009, 131, 16642-16643.

[50] a) S. E. Denmark, T. Bui, J. Org. Chem. 2005, 70, 10190-10193. b) Y. Hayashi, T. Itoh, S. Aratake, H. Ishikawa, Angew. Chem. Int. Ed. 2008 47, 2082-2084. c) S. Hu, L. Zhang, J. Li, S. Luo, J.-P. Cheng, Eur. J. Org. Chem. 2011, 3347-3352.

[51] L. Schreyer, P. S. J. Kaib, V. N. Wakchaure, C. Obradors, R. Properzi, S. Lee, B. List, Science 2018, 362, 216-219.

[52] M. B. Boxer, H. Yamamoto, J. Am. Chem. Soc. 2006, 128, 48-49.

[53] a) C. H. Cheon, H. Yamamoto, Chem. Commun. 2011, 47, 3043-3056. b) D. Parmar, E. Sugiono, S. Raja, M. Rueping, Chem. Rev. 2014, 114, 9047-9153.

[54] K. Kaupmees, N. Tolstoluzhsky, S. Raja, M. Rueping, I. Leito, Angew. Chem. Int. Ed. 2013, 52, 11569-11572.

[55] N. Tsuji, J. L. Kennemur, T. Buyck, S. Lee, S. Prévost, P. S. J. Kaib, D. Bykov, C. Farès, B. List, Science 2018, 359, 1501-1505.

[56] B. B. Snider, Comprehensive Organic Synthesis; B. M. Trost, I. Fleming, C H. Heathcock, Pergamon Press: New York, 1991; Vol. 2, pp 527-561.

[57] Selected examples: a) S. R. Crosby, J. R. Harding, C. D. King, G. D. Parker, C. L. Willis, Org. Lett. 2002, 4, 577-580. b) C. St. J. Barry, S. R. Crosby, J. R. Harding, R. A. Hughes, C. D. King, G. D. Parker, C. L. Willis, Org. Lett. 2003, 5, 2429-2432. c) A. J. Bunt, C. D. Bailey, B. D. Cons, S. J. Edwards, J. D. Elsworth, T. Pheko, C. L. Willis, Angew. Chem. Int. Ed. 2012, 51 3901-3904. d) M. J. Cloninger, L. E. Overman, J. Am. Chem. Soc. 1999, 121, 1092-1093. e) R. Jasti, J. Vitale, S. C. Rychnovsky, J. Am. Chem. Soc. 2004, 126, 9904-9905.

[58] Y. Xie, G-J. Cheng, S. Lee, P. S. J. Kaib, W. Thiel, B. List, J. Am. Chem. Soc. 2016, 138, 14538-14541.

[59] a) G. C. Tsui, L. Liu, B. List, Angew. Chem. Int. Ed. 2015, 54, 7703-7706. b) L. Liu, P. S. J. Kaib, A. Tap, B. List, J. Am. Chem. Soc. 2016, 138, 10822-10825. c) C. Lalli, P. van de Weghe, Chem. Commun. 2014, 50 7495-7498. d) J. Liu, J. Zhou, C. Wang, D. Liang, Z. Li, Y. Zou, Q. Wang, A. Goeke, Chem. Eur. J. 2016, 22, 6258-6261.

[60] A. C. Spivey, L. Laraia, A. R. Bayly, H. S. Rzepa, A. J. P. White, Org. Lett. 2010, 12, 900-903.

[61] T. L. Gresham, T. R. Steadman, J. Am. Chem. Soc. 1949, 71, 737-738.

[62] K. A. Jørgensen, Angew. Chem. Int. Ed. 2000, 39, 3558-3588.

[63] a) M. Bednarski, S. J. Danishefsky, J. Am. Chem. Soc. 1986, 108, 7060-7067. b) J. Guin, C. Rabalakos, B. List, Angew. Chem. Int. Ed. 2012, 51, 8859-8863. c) L. Lin, Y. Kuang, X. Liu, X. Feng, Org. Lett. 2011, 13, 3868-3871. d) Y. Huang, A. K. Unni, A. N. Thadani, V. H. Rawal, Nature, 2003, 424, 146. e) M. P. Doyle, M. Valenzuela, P. Huang, Proc. Natl. Acad. Sci. U. S. A. 2004, 101, 5391-5395.

[64] a) R. B. Woodward, R. Z. Hoffmann, The Conservation of Orbital Symmetry; Verlag Chemie: Weinheim, Germany, 1970. b) L. Fleming, Frontier Orbitals and Organic Chemical Reactions; Wiley: London, 1977.

[65] V. K. Aggarwal, G. P. Vennall, P. N. Davey, C. Newman, Tetrahedron Lett. 1997, 38, 2569-2572.

[66] L. Liu, H. Kim, Y. Xie, C. Farès, P. S. J. Kaib, R. Goddard, B. List, J. Am. Chem. Soc. 2017, 139, 13656-13659.

[67] H. Mayr, B. Kempf, A. R. Ofial, Acc. Chem. Res. 2003, 36, 66-77.

[68] H. Mayr, T. Bug, M. F. Gotta, N. Hering, B. Irrgang, B. Janker, B. Kempf, R Loos, A. R. Ofial, G. Remennikov, H. Schimmel, J. Am. Chem. Soc. 2001, 123, 9500-9512.

[69] a) M. Beller, J. Seayad, A. Tillack, H. Jiao, Angew. Chem. Int. Ed. 2004, 43, 3368-3398. b) V. Rodriguez-Ruiz, R. Carlino, S. Bezzenine-Lafollée, R. Gil, D. Prim, E. Schulz, J. Hannedouche, Dalt. Trans. 2015, 44, 12029-12059.

[70] a) Y. Nishiyama, T. Wada, S. Asaoka, T. Mori, T. A. McCarty, N. D. Kraut F. V. Bright, Y. Inoue, J. Am. Chem. Soc. 2008, 130, 7526-7527. b) C. S. Sevov, J. F. Hartwig, J. Am. Chem. Soc. 2013, 135, 9303-9306. c) J. Schlüter, M. Blazejak, F. Boeck, L. Hintermann, Angew. Chem. Int. Ed. 2015, 54, 4014-4017. d) H. Murayama, K. Nagao, H. Ohmiya 
M Sawamura, Org. Lett. 2015, 17, 2039-2041. e) H. Shigehisa, M. Hayashi, H. Ohkawa, T. Suzuki, H. Okayasu, M. Mukai, A. Yamazaki, R. Kawai, H. Kikuchi, Y. Satoh, A. Fukuyama, K. Hiroya, J. Am. Chem. Soc. 2016, 138, 10597-10604. f) Z. Yang, H. Li, S. Li, M.-T. Zhang, S. Luo, Org. Chem. Front. 2017, 4, 1037-1041.

[71] M. E. Jung, G. Piizzi, Chem. Rev. 2005, 105, 1735-1766.

[72] K. U. Wendt, K. Poralla, G. E. Schulz, Science 1997, 277, 1811-1815.

[73] S.-S. Gao, M. Garcia-Borràs, J. S. Barber, Y. Hai, A. Duan, N. K. Garg, K. N. Houk, Y. Tang, J. Am. Chem. Soc. 2017, 139, 3639-3642.

[74] a) B. List, R. A. Lerner, C. F. Barbas III, J. Am. Chem. Soc. 2000, 122, 2395-2396. b) S. Bahmanyar, K. N. Houk, H. J. Martin, B. List, J. Am Chem. Soc. 2003, 125, 2475-2479.

[75] Figure 7c was taken from the following publication with permission from Elsevier (license number 4504111108016): C. Liu, M. Yuan, X. Xu L. Wang, A. T. Keatinge-Clay, Z. Deng, S. Lin, J. Zheng, J. Struct. Biol. 2018, 203, 135-141. 


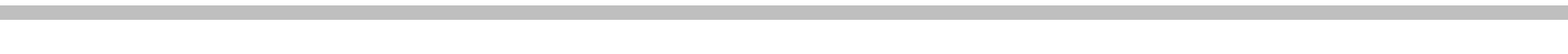

